\title{
Arquitectura pública del Arcaico Tardío en el valle de Fortaleza. Reflexiones sobre las sociedades complejas tempranas en la Costa Nor-Central
}

\author{
Rafael Vega-Centeno Sara-Lafosse*
}

Resumen En este texto se presentan los resultados de la prospección y mapeo de sitios con arquitectura monumental temprana de una sección del valle medio de Fortaleza. Se analiza la arquitectura de los sitios asignados tentativamente al período Arcaico Tardío, planteando algunas hipótesis sobre su desarrollo. Los sitios de Fortaleza son comparados con otros valles de la costa Nor-Central, planteándose que los complejos arquitectónicos existentes en esta región parecen corresponder a entidades sociopolíticas de alcance local, antes que a centros de alcance regional. Se concluye con algunas reflexiones sobre nuevas perspectivas teóricas para entender el surgimiento y desarrollo de estas sociedades.

Palabras Clave Costa Nor-Central, Arquitectura Monumental, Escala, Complejidad del Espacio, Montículo Piramidal, Plaza Circular.

\begin{abstract}
I present in this article the results of survey and mapping at sites with early monumental architecture in the Middle Fortaleza Valley. Architecture provisionally assigned to the Late Archaic period is analyzed, and some hypotheses on its development are proposed. The Fortaleza sites are then compared with other ones throughout the North Central Coast. I propose that the architectural complexes in this region seem to correspond to local-range sociopolitical entities, instead of large, regional polities. Finally, I conclude with some thoughts on new theoretical perspectives to understand the origins and development of such entities.
\end{abstract}

Keywords North Central Coast, Monumental Architecture, Scale, Spatial Complexity, Pyramid Mound, Circular Court.

\footnotetext{
*Profesor de la Universidad Nacional Mayor de San Marcos. Correo electrónicol: rvegacen@u.arizona.edu, fvega@pucp.edu.pe
} 
Este trabajo presenta los primeros resultados de las investigaciones del Proyecto Arqueológico Fortaleza, dirigido por el autor, llevadas a cabo en el valle del mismo nombre. Se hace un resumen de la información obtenida en la prospección y mapeo de sitios con arquitectura monumental temprana de la llamada Zona IV del valle medio de Fortaleza. Luego de una descripción de las evidencias registradas, se hace un análisis de la escala y complejidad de los sitios, a partir del cual se plantean algunas hipótesis sobre la naturaleza de las sociedades responsables de la construcción de la arquitectura estudiada.

Estos resultados son comparados con la información de otros valles vecinos, en particular el valle de Supe. Sobre la base de esta comparación, se busca sintetizar el estado de la cuestión del estudio del Arcaico Tardío para la denominada "Costa Nor-Central". Finalmente, se plantean algunas reflexiones teóricas para contextualizar el estudio de estas sociedades en el marco de la reflexión internacional sobre el surgimiento de sociedades complejas.

La Costa Nor Central está ubicada entre los 150 a $205 \mathrm{~km}$ al norte de la ciudad de Lima, e incluye a los valles de Huaura, Supe, Pativilca y Fortaleza. La cercanía de los tres últimos permite la formación de una franja fértil de $25 \mathrm{~km}$, denominada "Complejo de Pativilca" por Paul Kosok. Fue este mismo autor quien llamó la atención acerca de impresionantes complejos arquitectónicos tempranos en el valle de Supe (Kosok 1965:217-223).

La documentación de sitios tempranos con arquitectura monumental en el valle de Supe, se enriqueció notablemente con el trabajo catastral llevado a cabo por el Instituto Nacional de Cultura (Williams y Merino 1979). En este trabajo se identificaron alrededor de 20 sitios de estas características, que brindaron nuevas perspectivas al estudio de las primeras tradiciones arquitectónicas andinas (Williams 1980:405-407). Casi simultáneamente, Robert Feldman dio cuenta de la presencia de sitios con características semejantes en los valles de Pativilca (5 sitios) y Fortaleza (3 sitios) (Feldman 1980:Fig. 2). Esta información fue posteriormente refrendada por Carlos Williams para el valle de Pativilca (Williams 1985, 1988). Recientemente, el autor, en compañía de Luis Felipe Villacorta, Luis Cáceres y Giancarlo Marcone, amplió la muestra de sitios tempranos en el valle de Fortaleza (Vega-Centeno et.al. 1998). Asimismo, el Proyecto Arqueológico Caral, bajo la dirección de Ruth Shady, ha proporcionado mayor información acerca de los sitios tempranos del valle de Supe, presentando planos de los sitios previamente documentados (Shady et al. 2000).

En contraste con la abundante información proveniente de reconocimientos superficiales, las excavaciones han sido escasas. El sitio de Áspero, en el valle bajo de Supe, adquirió notoriedad por ser uno de los pocos sitios de estas características excavado antes de la década del noventa (Feldman 1980, 1985, 1987; Moseley y Willey 1973; Willey y Corbett 1954). Recientemente, los trabajos dirigidos por Shady en los sitios de Caral y Chupacigarro (Shady 2000; Shady y Leyva 2003) han llevado a replantear anteriores consideraciones sobre la arquitectura pública temprana de esta región, en particular en lo que concierne a su ubicación cronológica (v.g., Burger 1992:76; Kaulicke 1994:298; Lumbreras 1989:109; Vega-Centeno et. al. 1998:229-231). Junto con los continuos trabajos del Proyecto Arqueológico Caral, se vienen desarrollando otros dos proyectos arqueológicos en la región: El Proyecto Norte Chico, en los valles de Pativilca y Fortaleza, a cargo de Jonathan Haas y Álvaro Ruiz; y el Proyecto Fortaleza, a cargo del autor, en el valle del mismo nombre.

Puede decirse que el estudio de las sociedades tempranas en la Costa Nor-Central se encuentra en una etapa expectante, con tres proyectos trabajando la misma problemática en forma simultánea. Los resultados de esta confluencia de iniciativas deben empezar a verse en los siguientes años. En esa dirección, se presen- 


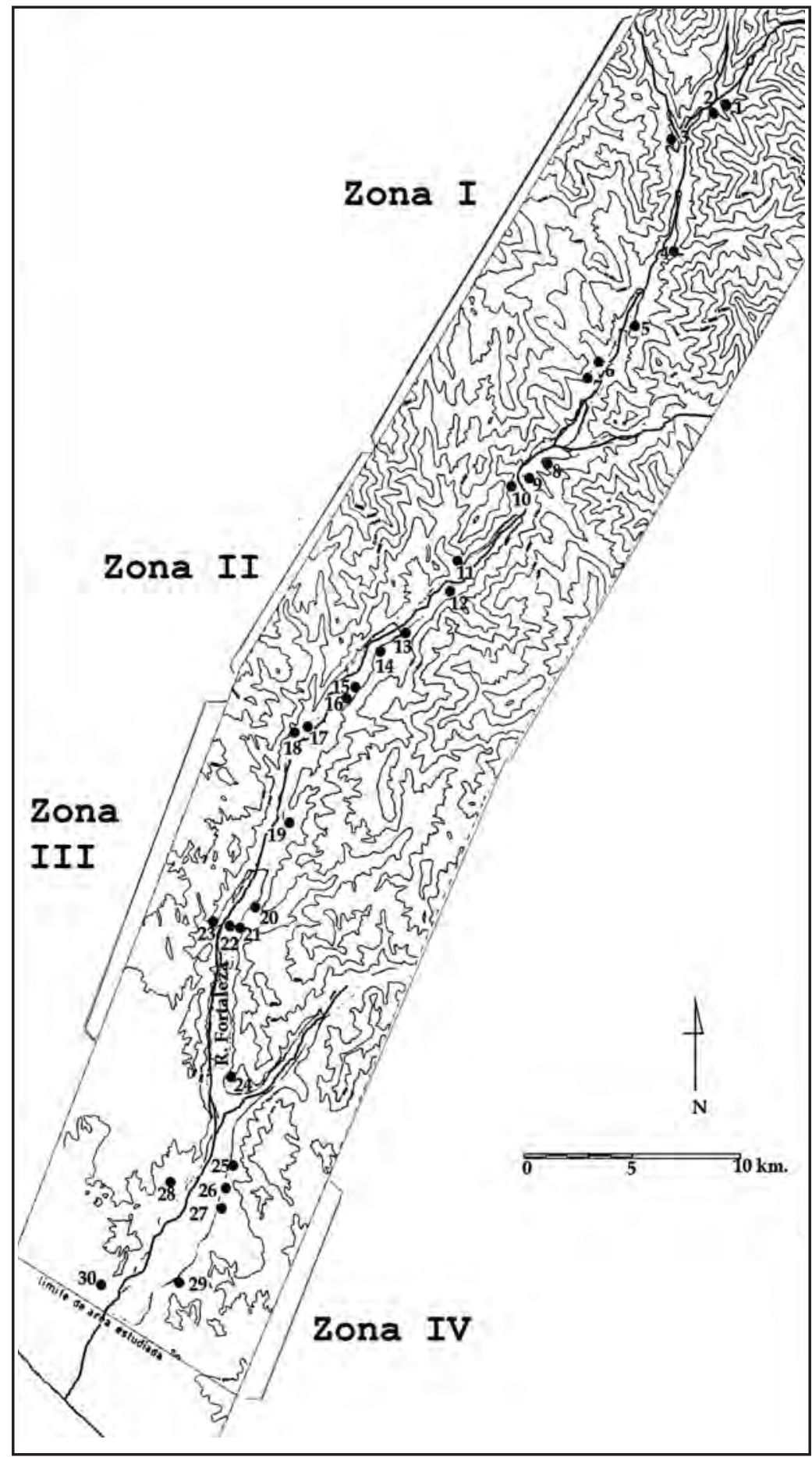

Figura 1. Mapa del valle medio de Fortaleza. Ubicación de los treinta sitios identificados con arquitectura temprana. 
tan los primeros resultados de los trabajos en la Zona IV del valle medio de Fortaleza, dirigidos por el autor en el año $2002^{1}$.

\section{La arquitectura público-ceremonial tempra- na en la Zona IV de Fortaleza}

El valle medio de Fortaleza se encuentra en el límite de los departamentos de Lima y Ancash. Comprende una franja fértil de $60 \mathrm{~km}$ de largo ubicada entre los 25 y 1600 m.s.n.m. Esta región puede dividirse en cuatro zonas diferenciadas por su topografía, clima y tipos de suelos (VegaCenteno et al. 1998:220-222). A lo largo de estas zonas, se han podido identificar un total de treinta sitios con arquitectura temprana que puede ser definida como de carácter público y/o ceremonial (Figura. 1).

Las evidencias de superficie sólo permiten una asignación cronológica tentativa y, además, bastante gruesa de los sitios. Elementos arquitectónicos, tales como montículos piramidales asociados con plazas circulares hundidas, asemejan a los edificios encontrados en el vecino valle de Supe y, en particular, a las estructuras del sitio de Caral, recientemente asignadas al Arcaico Tardío (Shady et al. 2000). Por su parte, estructuras de plataformas adosadas a lo largo de un eje longitudinal y articuladas a una estructura piramidal en uno de sus extremos, asemejan las estructuras del Formativo Temprano en los valles de Casma y Huarmey (Álvarez y Espinoza 1997; Pozorski y Pozorski 1987; Williams 1972). Estos indicadores sugieren que los sitios inicialmente asignados al Formativo Temprano (Vega-Centeno et al. 1998:229-230) pueden ser asignados a más de un período. En tal sentido, las investigaciones en el valle medio de Fortaleza están orientadas, entre otras cosas, a precisar la ubicación temporal de las diferentes tradiciones arquitectónicas tempranas allí desarrolladas, en el marco de un estudio mayor, sobre la naturaleza del surgimiento de formaciones sociales complejas.
Como etapa previa al desarrollo de excavaciones, se levantaron planos de trece de los treinta sitios identificados en $1996^{2}$, incluyendo todos los sitios de lo que hemos llamado Zona IV del valle medio. La Zona IV es un área caracterizada por el ensanchamiento de la planicie aluvial y la reducción de la pendiente a lo largo y ancho del valle. Dentro de esta zona se pudieron identificar siete sitios con arquitectura pública temprana (Figura 2). Estos son los sitios de Tunán, Cerro Blanco Norte, Cerro Blanco Centro, Cerro Blanco Sur, Caballete, Cerro Lampayy Porvenir.

Dentro de estos sitios fue posible identificar ocho tipos de unidades arquitectónicas. Cinco de estos tipos corresponden a unidades de volumen. Es decir, unidades que definen espacios a partir de la construcción de planos elevados. Por otro lado, tres tipos corresponden a unidades de área, o unidades que definen espacios a partir de la modificación de la superficie del terreno.

Las unidades de volumen son:

1. Plataforma aterrazada.

2. Plataforma simple.

3. Montículo piramidal simple.

4. Montículo piramidal con "atrio" en la cima.

5. Montículo piramidal con "atrio" intermedio. Por su parte, las unidades de área son:

1. Plaza cuadrangular hundida.

2. Plaza circular hundida.

3. Patio rectangular.

En base a la identificación de estas unidades, se pueden definir estructuras arquitectónicas como los espacios discretos generados a partir de la articulación de una o más de las unidades antes mencionadas.

El Cuadro 1 presenta las estructuras arquitectónicas de los sitios de la Zona IV, indicando el número y tipo de las unidades componentes en cada estructura. Asimismo, presenta las dimensiones de área de las estructuras en su conjunto, así como una estimación tentativa de las dimensiones en las unidades de volumen.

\footnotetext{
${ }^{1}$ Estos trabajos fueron patrocinados y financiados por la Dirección Académica de Investigación de la Pontificia Universidad Católica del Perú.

${ }^{2}$ Los planos fueron hechos con apoyo de una estación total Pentax 315. Incluyeron la indicación de elementos arquitectónicos visibles, así como del entorno topográfico de los conjuntos identificados.
} 
Como puede observarse, los sitios pueden clasificarse en tres estructuras aisladas (Tunán, Cerro Blanco Norte y Cerro Lampay) y cuatro complejos arquitectónicos de tres (Cerro Blanco Sur), cinco (Cerro Blanco Centro), doce (Caballete) y trece (Porvenir) estructuras arquitectónicas.

\section{Cronología Tentativa}

Cualquier intento por entender la organización espacial de una región requiere de la identificación de tipos arquitectónicos susceptibles de ser considerados contemporáneos. En tal sentido, en el caso de la Zona IV de Fortaleza, se pueden distinguir dos patrones arquitectónicos muy marcados. Uno se

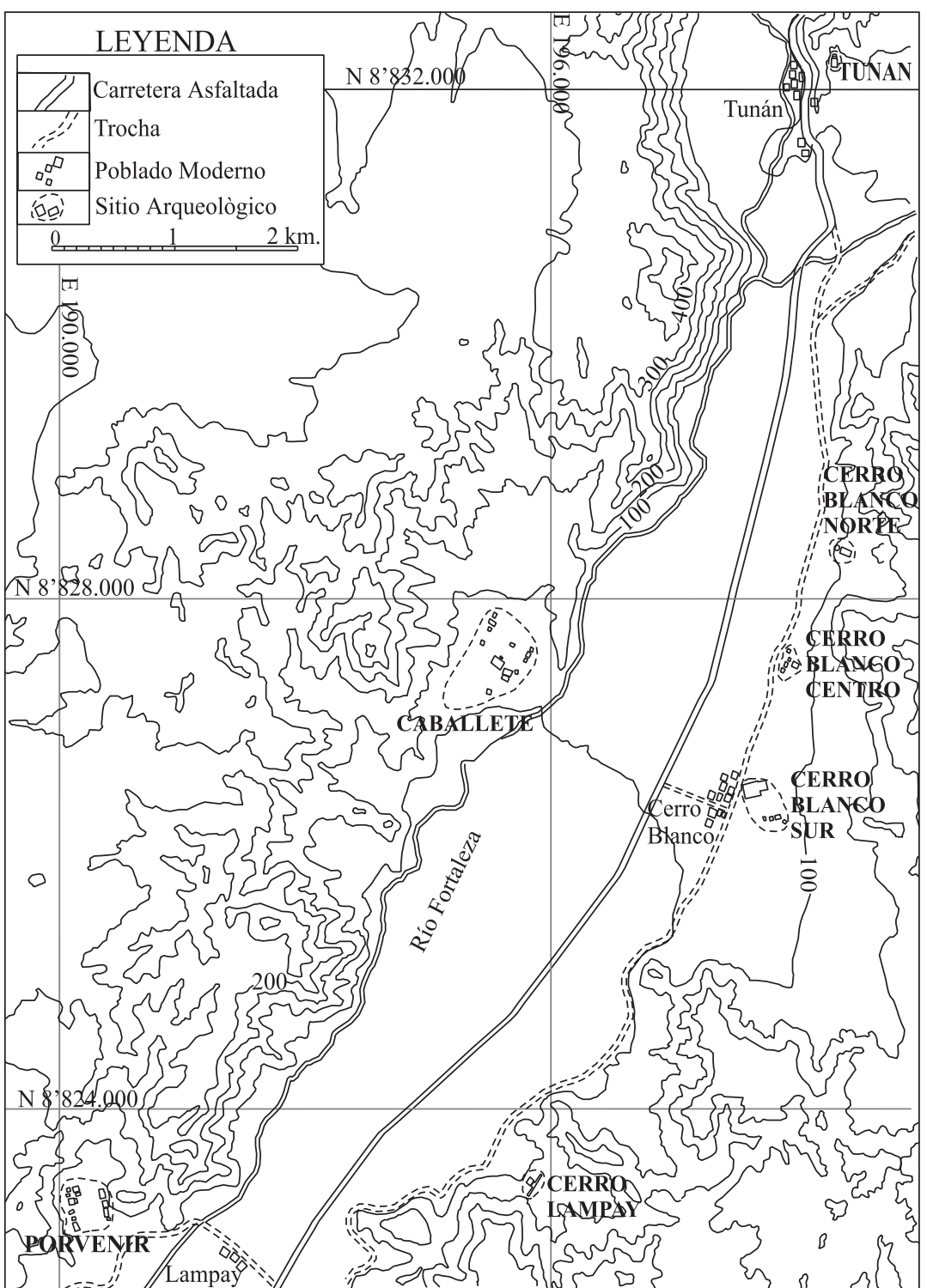

Figura 2. Mapa de la Zona IV del valle medio de Fortaleza que muestra la ubicación de los siete sitios identificados con arquitectura temprana. caracteriza por la construcción de montículos o plataformas de pendiente pronunciada, eventualmente asociadas con patios o plazas hundidas. El otro patrón es de construcción de plataformas asentadas sobre las faldas de cerros, articuladas con uno o más patios dentro de los cuales pueden encontrarse plazas hundidas. Como indicamos anteriormente, ambos patrones pueden ser relacionados con tradiciones arquitectónicas de distintos períodos. El primero asemeja a las evidencias diagnósticas del Arcaico Tardío en la Costa NorCentral (Feldman 1980, Shady et.al. 2000, Williams 1980 y 1988), mientras que el segundo parece relacionarse con las tradiciones arquitectónicas d el Formativo Temprano (Pozorski y Pozorski 1987, VegaCenteno 1995, 1999). 


\section{Cuadro 1}

\begin{tabular}{|c|c|c|c|c|c|c|c|c|c|c|c|}
\hline \multirow[t]{2}{*}{ Sitio } & \multirow{2}{*}{$\begin{array}{l}\text { Número } \\
\text { De } \\
\text { Estructura }\end{array}$} & \multicolumn{5}{|c|}{$\begin{array}{l}\text { Tipo de unidad } \\
\text { de volumen }\end{array}$} & \multicolumn{3}{|c|}{$\begin{array}{c}\text { Tipo de } \\
\text { unidad de área }\end{array}$} & \multirow{2}{*}{\begin{tabular}{|c|} 
Volumen \\
$\left(\mathrm{en}^{3}\right)^{*}$
\end{tabular}} & \multirow{2}{*}{$\begin{array}{c}\begin{array}{c}\text { Área } \\
\text { total }\end{array} \\
\left(\mathrm{en} \mathrm{m}^{2}\right) \\
\end{array}$} \\
\hline & & 1 & 2 & 3 & 4 & 5 & 1 & 2 & 3 & & \\
\hline Tunán & 1 & 1 & & & & & 1 & & & 5600 & 5643 \\
\hline Cerro Blanco Norte & 1 & & & & & 1 & & 1 & & 71062 & 5819 \\
\hline Cerro Blanco Centro & 1 & & & & & 1 & 1 & & & 25579 & 2821 \\
\hline Cerro Blanco Centro & 2 & & & & & 1 & & & 1 & 2830 & 732 \\
\hline Cerro Blanco Centro & 3 & & & & & 1 & & & 1 & 7758 & 1326 \\
\hline Cerro Blanco Centro & 4 & & & & & 1 & & & 1 & 5913 & 1327 \\
\hline Cerro Blanco Centro & 5 & & 1 & & & & & & 1 & 150 & 552 \\
\hline Cerro Blanco Sur & 1 & 3 & & 1 & & & & & 4 & $\mathrm{NA}^{* *}$ & 16050 \\
\hline Cerro Blanco Sur & 2 & 1 & & & & & & & 1 & $\mathrm{NA}^{* *}$ & 3349 \\
\hline Cerro Blanco Sur & 3 & & 1 & & & & & & & $\mathrm{NA}^{* *}$ & 394 \\
\hline Caballete & 1 & & & & 1 & & & & & 14490 & 2070 \\
\hline Caballete & 2 & & 1 & & & & & & & 1344 & 448 \\
\hline Caballete & 3 & & 1 & & & & & & & 2610 & 870 \\
\hline Caballete & 4 & & 1 & & & & & & & 1856 & 928 \\
\hline Caballete & 5 & & & & 1 & & & 1 & 1 & 25620 & 9030 \\
\hline Caballete & 6 & & & & 1 & & & 1 & & 123280 & 8029 \\
\hline Caballete & 7 & & & & & & 1 & & & $\mathrm{NA}^{* *}$ & 1190 \\
\hline Caballete & 8 & & & 1 & & & & & & 3360 & 840 \\
\hline Caballete & 9 & & 1 & & & & & & & 1472 & 736 \\
\hline Caballete & 10 & & & & 1 & & & 1 & & 12408 & 2794 \\
\hline Caballete & 11 & & 1 & & & & & & & 1980 & 990 \\
\hline Caballete & 12 & & 1 & & & & & & 2 & 720 & 580 \\
\hline Cerro Lampay & 1 & & & 1 & & & & 1 & & 5890 & 3387 \\
\hline Porvenir & 1 & & 1 & 1 & & & & & & 11139 & 2788 \\
\hline Porvenir & 2 & & & & 1 & & & & & 8010 & 2003 \\
\hline Porvenir & 3 & & 2 & 1 & & & & & & 1296 & 432 \\
\hline Porvenir & 4 & & & & 1 & & & 1 & & 30000 & 7325 \\
\hline Porvenir & 5 & & & 1 & & & & & & 5280 & 960 \\
\hline Porvenir & 6 & & & 1 & & & & & & 3000 & 750 \\
\hline Porvenir & 7 & & & & 1 & & & 1 & & 10086 & 2653 \\
\hline Porvenir & 8 & & & 1 & & & & & & 750 & 150 \\
\hline Porvenir & 9 & & & 1 & & & & & & 4800 & 960 \\
\hline Porvenir & 10 & & 1 & & & & & & & $\mathrm{NA}^{* *}$ & 2670 \\
\hline Porvenir & 11 & & & 1 & & & & & & 560 & 280 \\
\hline Porvenir & 12 & & 1 & & & & & & & $\mathrm{NA}^{* *}$ & 966 \\
\hline Porvenir & 13 & & 1 & & & & & & & $\mathrm{NA}^{* *}$ & 288 \\
\hline
\end{tabular}

*Las cantidades no corresponden al volumen real, sino al producto del área de las unidades de volumen por su altura máxima.

**No se puede definir su altura máxima. 


\section{El Arcaico Tardío en la Zona}

IV. Descripción de las evidencias arquitectónicas

Para los fines de esta presentación, se opta por restringir la muestra a los cinco sitios asignables al Arcaico Tardío, con el fin de lograr una aproximación sincrónica a la organización espacial de la Zona IV. Nos referimos a los sitios de Cerro Blanco Norte, Cerro Lampay, Cerro Blanco Centro, Porvenir y Caballete.

Cerro Blanco Norte (Figura 4) está compuesto por una sola estructura. Ésta se compone de un montículo orientado hacia el Noroeste, construido sobre un promontorio natural de forma alargada (Figura 3). El montículo se compone de por lo menos tres plataformas, teniendo la plataforma intermedia un área delimitada en tres de sus lados, comparable con un "atrio". El montículo se asocia a una plaza circular hundida.

Cerro Lampay (Figura 5) se compone de un montículo de forma cuadrangular, orientado hacia el Noroeste, parcialmente asentado sobre una terraza natural. Este montículo está asociado con un patio de grandes dimensiones, en medio del cual encontramos una plaza circular hundida (Figura 7). Por otro lado, existe un extenso muroplataforma adosado a la parte posterior del montículo.

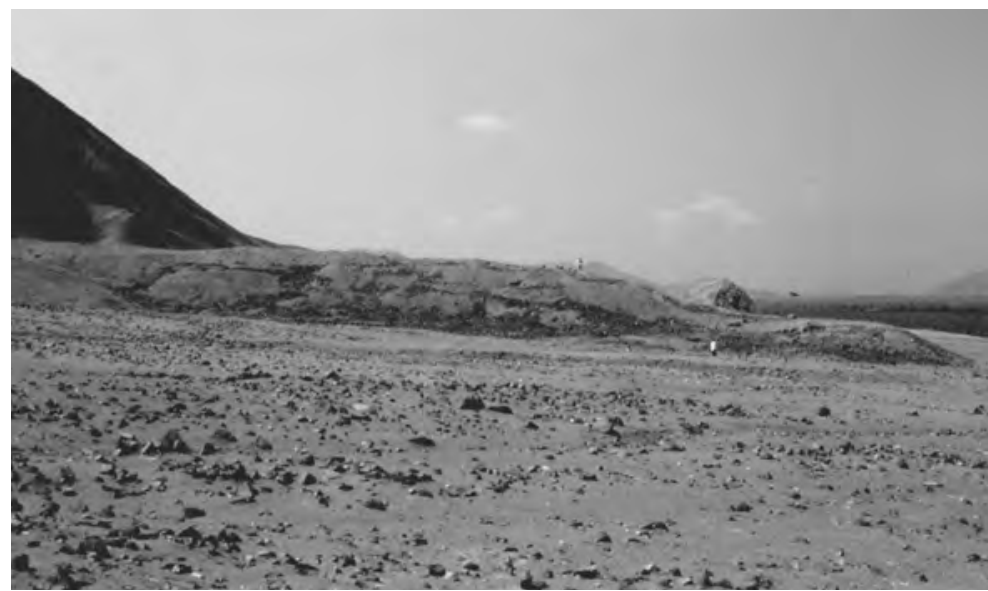

Figura 3. Vista de la estructura arquitectónica de Cerro Blanco Norte desde el Noreste.

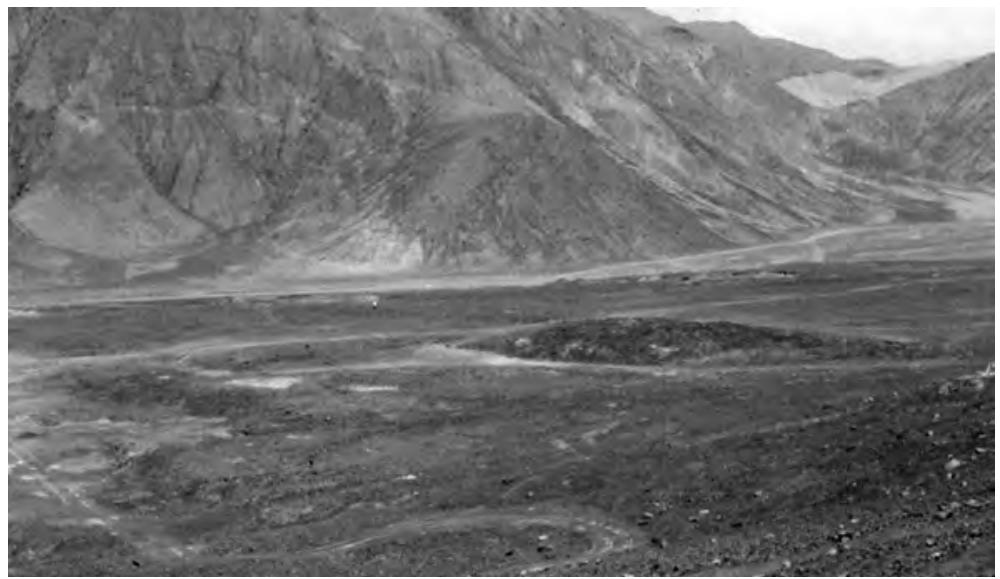

Figura 7. Vista panorámica de la estructura arquitectónica de Cerro Lampay.

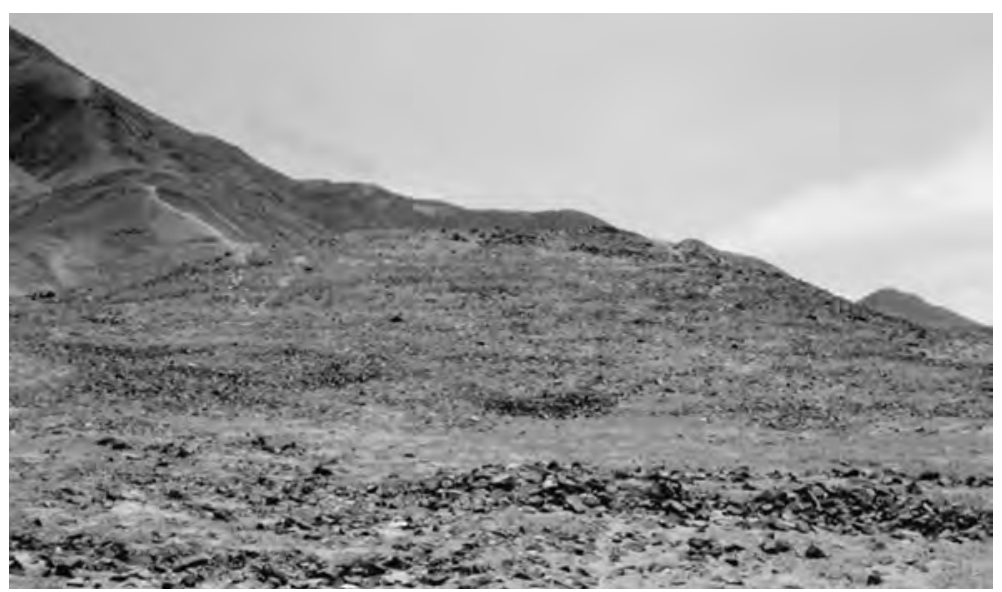

Figura 8. Vista frontal de la Estructura 2 de Cerro Blanco Centro. 

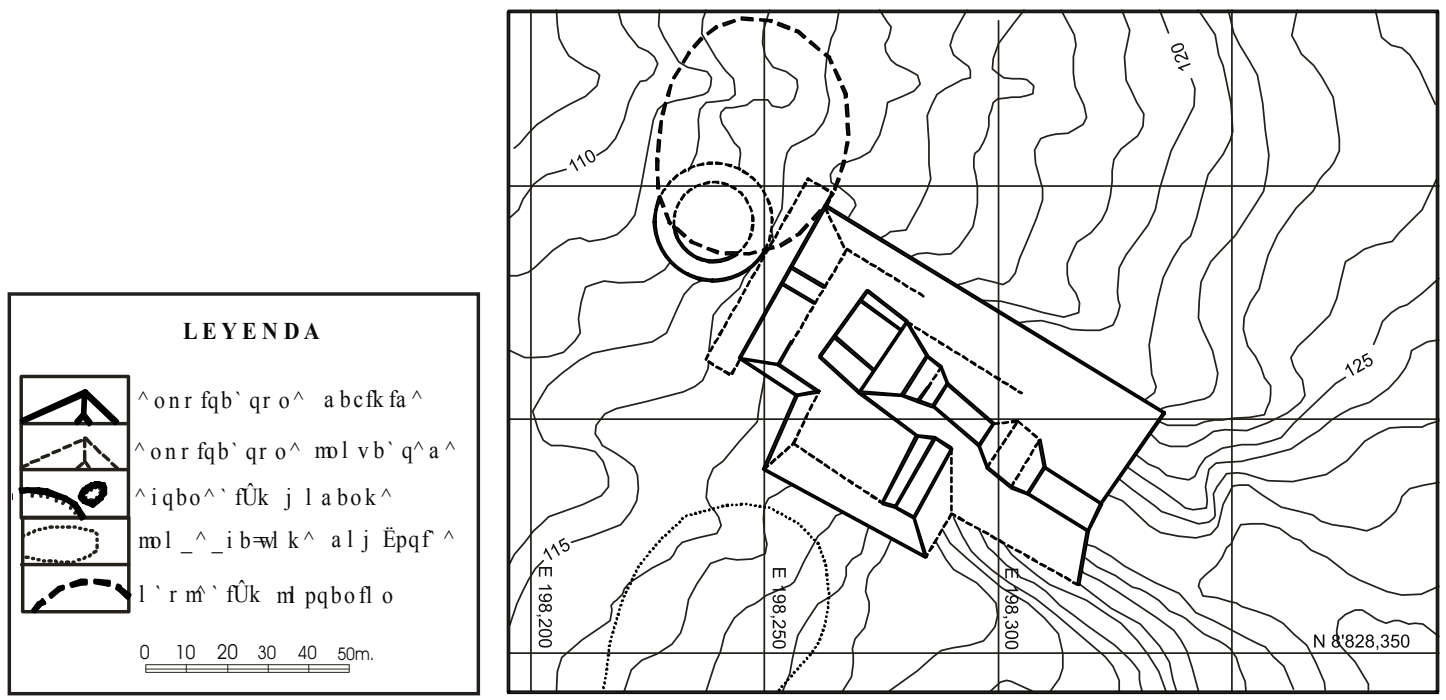

Figura 4. Plano del sitio de Cerro Blanco Norte.
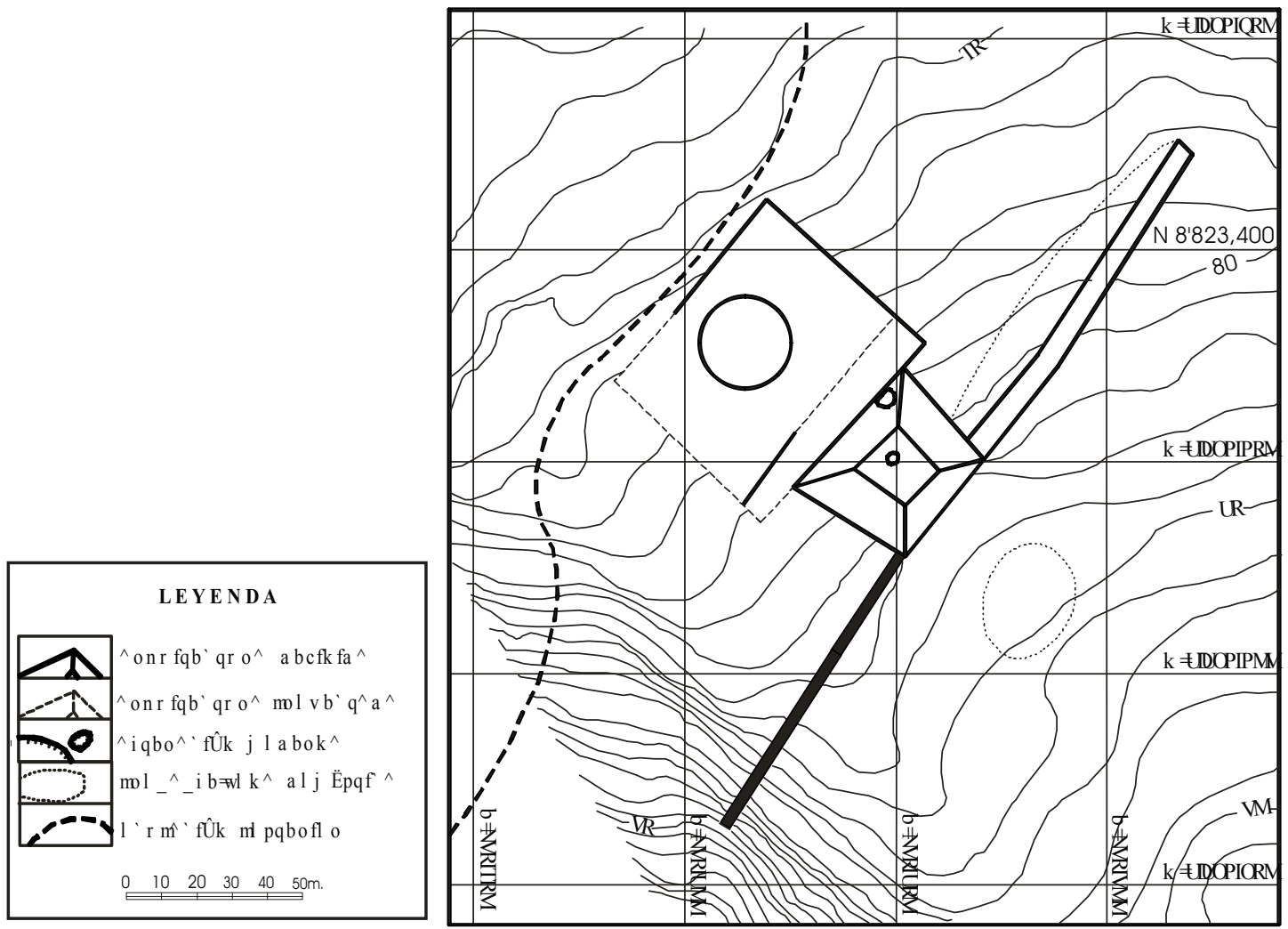

Figura 5. Plano del sitio de Cerro Lampay. 
Cerro Blanco Centro (Figura 6) es un complejo arquitectónico compuesto de cinco estructuras. La estructura de mayor tamaño (Estructura 1) cuenta con un montículo-plataforma asentado sobre la ladera de un cerro vecino. Este montículo cuenta con un área intermedia a desnivel (a manera de atrio) y se asocia con una pequeña plaza cuadrangular hundida. Delante de esta estructura encontramos tres estructuras compuestas por montículos cuadrangulares con una o más terrazas, asociadas a pequeños patios rectangulares delanteros (Estructuras 2, 3 y 4) (Figuras 8-9). Por último, encontramos una estructura de menor escala (Estructura 5), compuesta por una pequeña plataforma flanqueada por dos explanadas rectangulares y un patio rectangular mayor.

Porvenir es un complejo que involucra trece estructuras (Figuras 10 y 11). Destaca en este sitio una estructura compuesta por un montículo con un "atrio" central en la cima, que se asocia a un patio con plaza circular hundida (Estructura 4). Hacia el oeste de esta estructura encontramos un montículo de menor tamaño (Estructura 5). Al sur de éste, nos encontramos con otro montículo con un ala anexa (Estructura 6) que se une a un montículo con "atrio" central y plaza circular

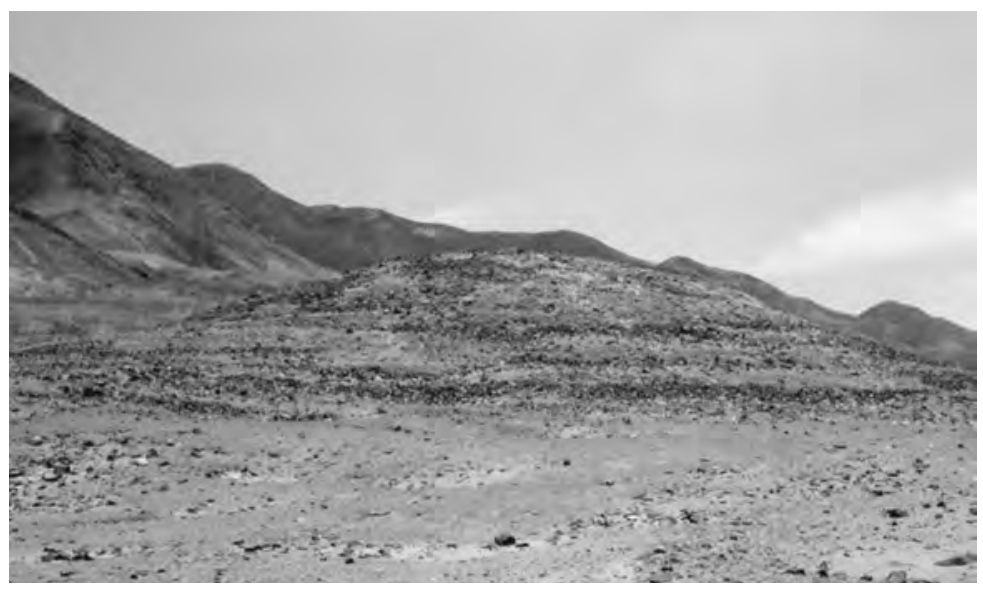

Figura 9. Vista frontal de la Estructura 3 de Cerro Blanco Centro.

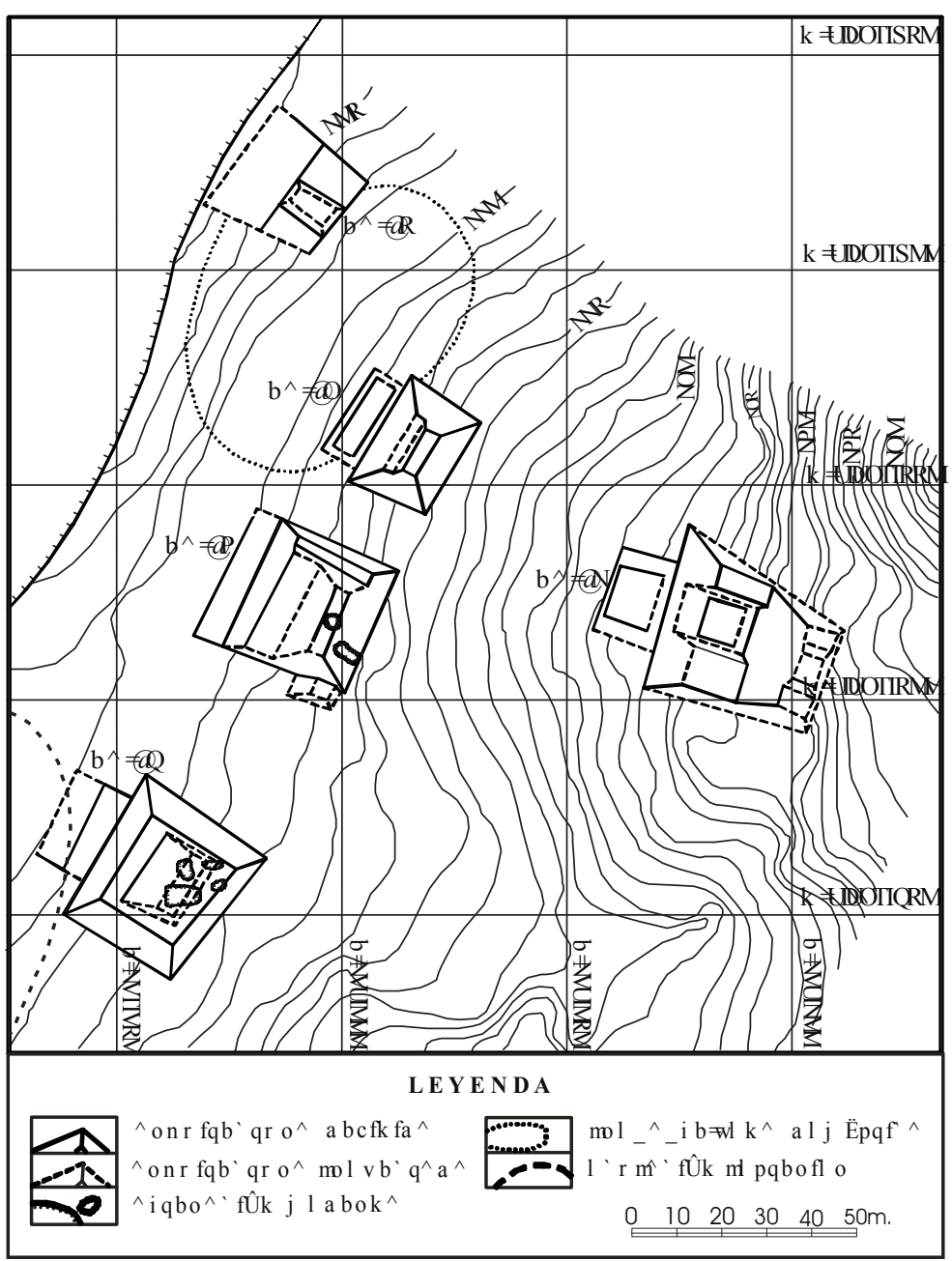

Figura 6. Plano del sitio de Cerro Blanco Centro. 


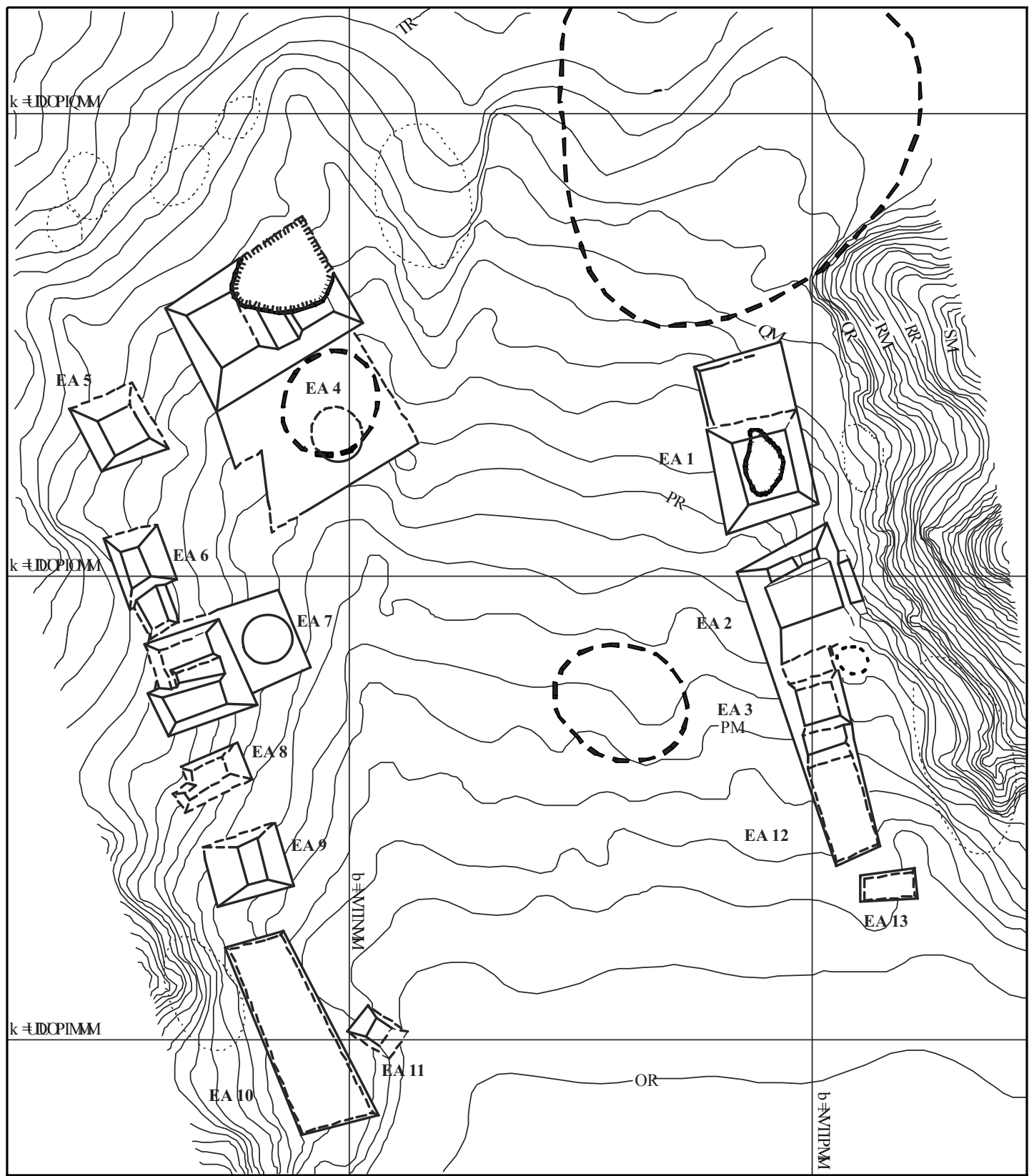

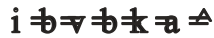
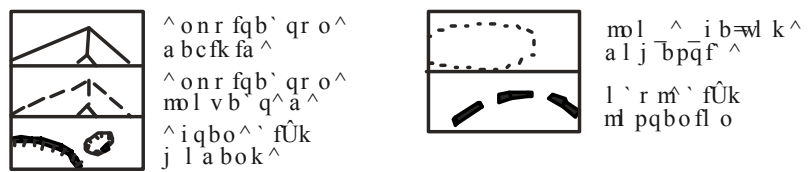

Figura 10. Plano del sitio de Porvenir. 
(Estructura 7), (Figura 12). En el mismo eje, siempre hacia el sur, encontramos tres estructuras más del tipo "montículo piramidal" (Estructuras 8,9 y 11 ), así como una plataforma simple (Estructura 10). A unos $150 \mathrm{~m}$ al este de la Estructura 4, encontramos otro conjunto de estructuras alineadas. Se trata de tres montículos piramidales (Estructuras 1, 2 y 3) y dos plataformas simples (Estructuras 12 y 13). Como detalles singulares, debe mencionarse que la Estructura 1 cuenta con una plataforma o patio lateral, mientras que la estructura 2 presenta su lado norte "elevado".

Caballete se compone de 12 estructuras arquitectónicas (Figuras 13 y 14). En el centro del complejo, nos encontramos con una estructura de grandes dimensiones, asociada con una plaza circular delimitada por piedras de gran tamaño dispuestas en forma vertical (Estructura 6). Hacia el Sureste, encontramos otro montículo asociado con un patio con plaza circular hundida (Estructura 5), así como una estructura más pequeña, muy destruida (Estructura 4). Siguiendo el eje de la Estructura 6, en dirección opuesta, encontramos otro montículo, a unos $100 \mathrm{~m}$ hacia el Noroeste (Estructura 8). Asimismo, a unos $80 \mathrm{~m}$ al noreste de la Estructura 8, encontramos

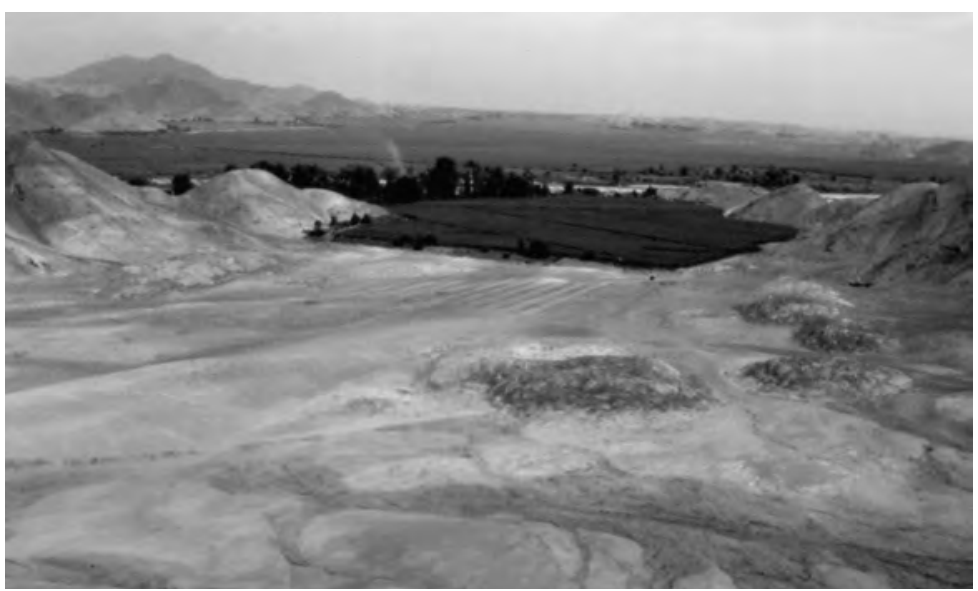

Figura 11. Vista panorámica del sitio de Porvenir.

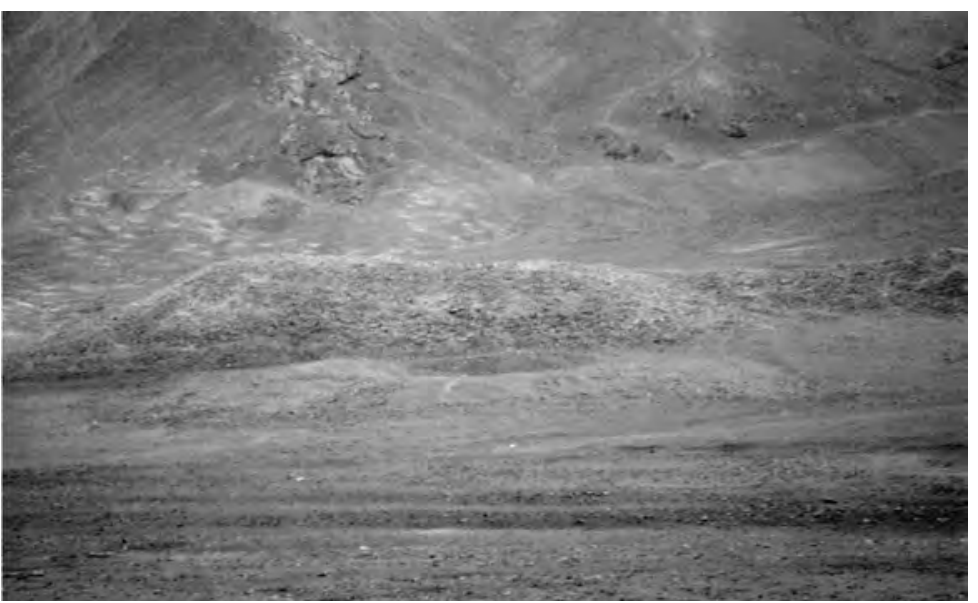

Figura 12. Vista frontal de la Estructura 7 de Porvenir.

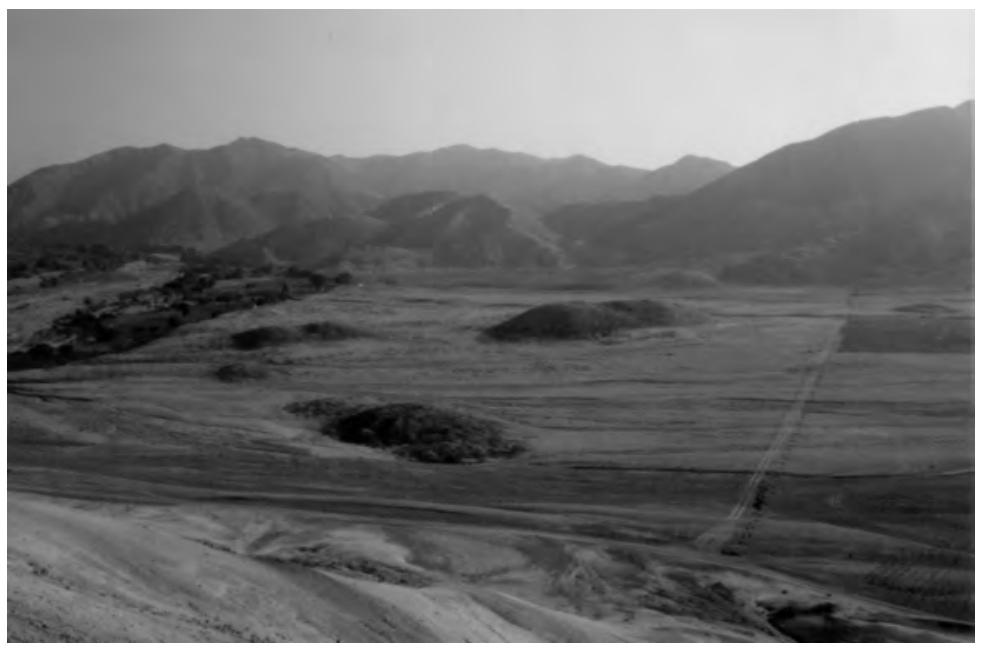

Figura 14. Vista panorámica del sitio de Caballete. 


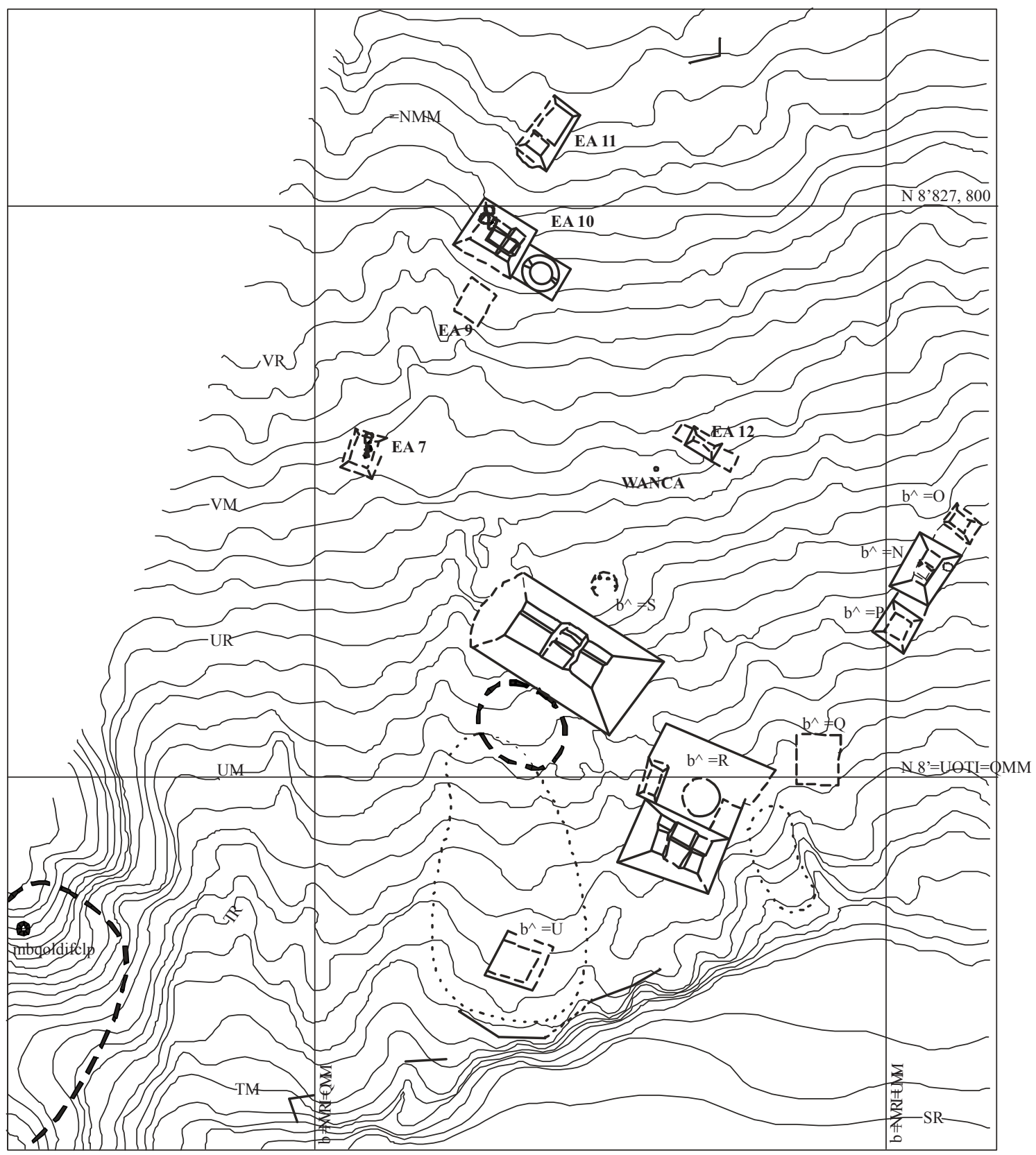

$\mathbf{i} \boldsymbol{b} \boldsymbol{\nabla} \boldsymbol{b} \mathbf{k}=\mathbf{z}$
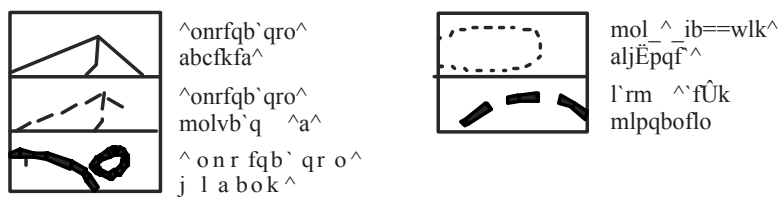

Figura 13. Plano del sitio de Caballete. 


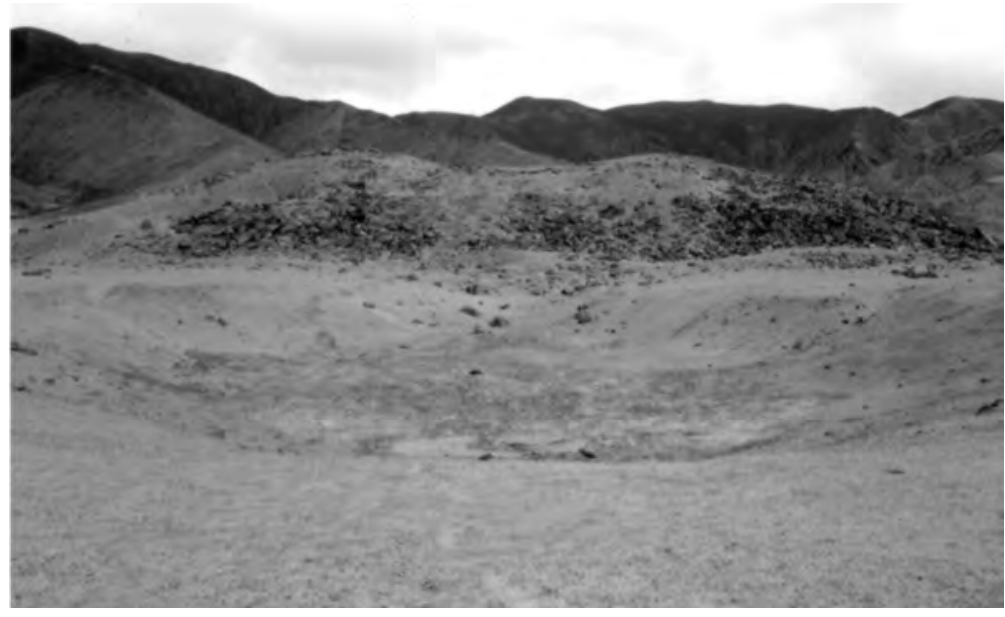

Figura 15. Vista frontal de la Estructura 10 de Caballete.

rios para actividades públicas, es decir, ante un segmento limitado de las actividades sociales de los pobladores de la zona.

Si estamos hablando de espacios públicos, es razonable considerarlos como centros de actividades de diversa índole (es común considerarlos como espacios de actividades ceremoniales) que congregan a grupos humanos por encima del ámbito doméstico. No es difícil relacionar este tipo de

una plataforma baja (Estructura 9), un montículo con plaza circular hundida (Estructura 10) (Figura 15) y una plataforma con dos niveles (Estructura 11). De manera paralela, a unos 60 $\mathrm{m}$ al noreste de la Estructura 4, encontramos dos montículos pequeños (Estructuras 2 y 3), flanqueando un montículo de mayor tamaño (Estructura 1). Por último, a mitad de camino entre las Estructuras 1 y 10, encontramos un pequeño montículo flanqueado por dos patios (Estructura 12). Este complejo se completa con una plaza cuadrangular hundida ubicada hacia el Sur (Estructura 7), dos probables muros perimétricos (en los extremos sur y norte), y una piedra con petroglifos.

\section{Escala, complejidad y organización del espacio}

Resulta difícil identificar evidencias del Arcaico Tardío en superficie, con excepción de construcciones de gran escala. Por tal motivo, entender la organización zonal de esta parte del valle de Fortaleza sobre la base de los sitios identificados, requiere de algunas precisiones. En principio, su distribución espacial en la Zona IV refleja fundamentalmente la distribución de espacios públicos en el territorio, antes que los patrones de asentamiento para el período en cuestión. En efecto, al tratarse de sitios con arquitectura monumental, estamos ante escena- actividades públicas con la gestación y consolidación de relaciones de poder. De allí la usual connotación política que adquieren estos espacios como "centros de poder".

Sobre esta base, entender la organización espacial de la Zona IV implica contemplar dos posibles escenarios. Uno con varias entidades políticas equivalentes, de funcionamiento autónomo, operando en cada uno de estos centros. El otro escenario es de un centro dominante, ubicado en la cima de una red jerárquica, con los otros sitios en posición subordinada, como entidades secundarias o, incluso, terciarias. Comúnmente, la opción por uno u otro escenario depende de la identificación de diferencias en escala y complejidad entre los centros. La ausencia de dichas diferencias aboga por el primer escenario, mientras que la identificación de diferencias conlleva a asumir el segundo.

Las diferencias en el número de estructuras, así como en la escala de los conjuntos en general, hacen difícil considerar al primer escenario. En efecto, el Cuadro 2 muestra la distribución de los cinco sitios en función del total del área construida y el número de estructuras. Podemos observar que existe una división marcada entre dos sitios con más de 20 hectáreas de terreno construido y otros tres de menos de una hectárea. Esta división se correlaciona parcialmente 


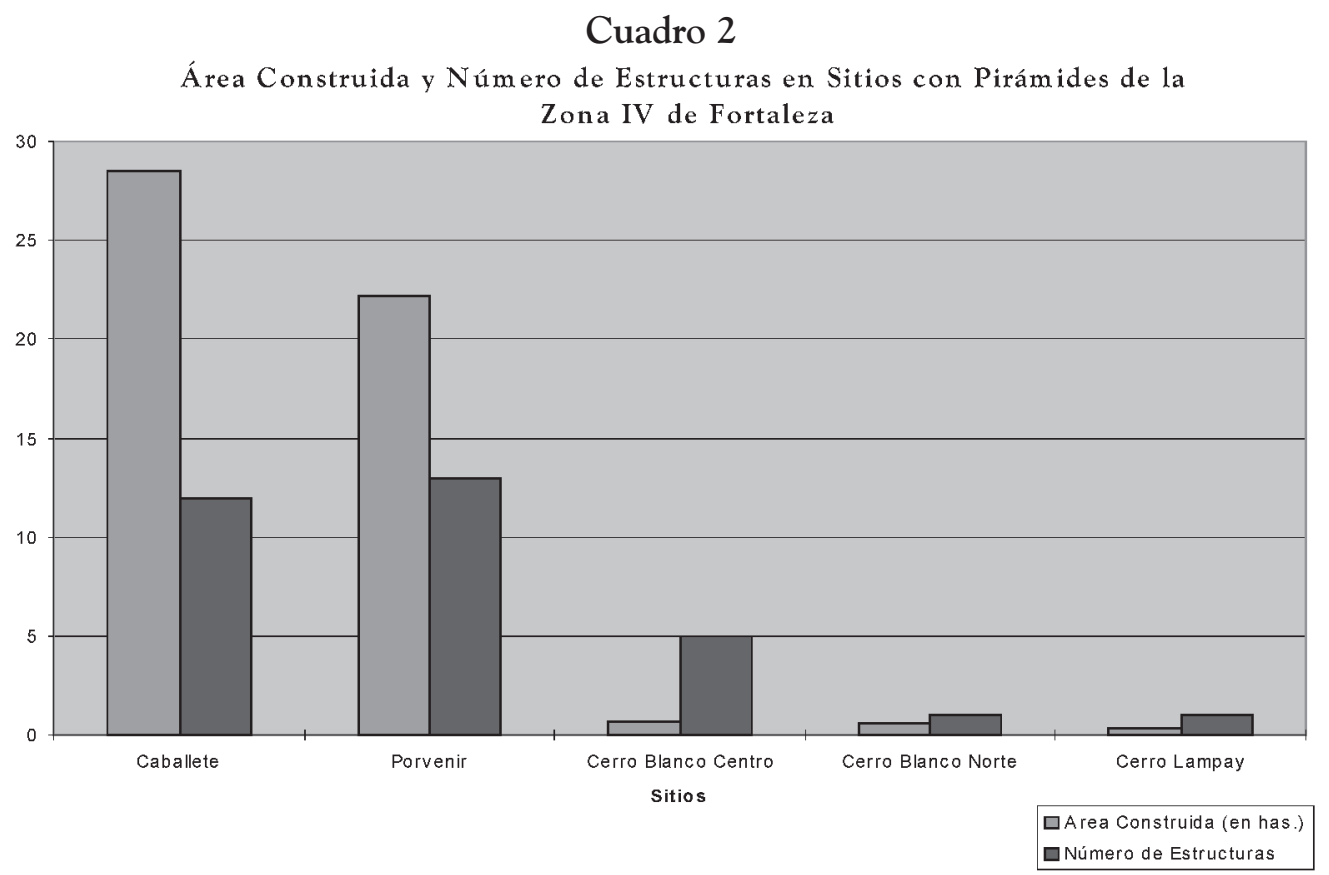

con el número de estructuras asignadas a cada sitio. En este caso, tenemos dos sitios con más de 10 estructuras, uno con cinco estructuras y dos con una sola estructura.

Si bien el estimado general del área construida para cada sitio puede sugerirnos un escenario jerarquizado, un examen más detallado de las características de las estructuras arquitectónicas nos muestra una realidad más compleja.

Como hemos mencionado, el principio de diferencia jerárquica se basa en diferencias de escala y complejidad. En términos de escala, deberíamos esperar que las estructuras de los sitios con mayor área construida fuesen claramente más grandes que los de menor área construida. Esta situación, sin embargo, no es tan clara. En el Cuadro 3 podemos observar la distribución de estructuras de los cinco sitios analizados de acuerdo con el área construida para cada una.

En este cuadro observamos que las estructuras de Cerro Blanco Norte y Cerro Lampay se encuentran entre las cinco estructuras de mayor área, siendo sólo superadas por dos estructuras de Caballete y una de Porvenir. Tenemos así que los dos sitios con estructuras aisladas, candidatos a ubicarse en un rango inferior de la red jerárquica, superan en escala al 90\% de las estructuras de la Zona IV.

Esta situación es particularmente manifiesta en el caso de Cerro Blanco Centro, en relación con los sitios de Cerro Blanco Norte y Cerro Lampay. Si bien el primero supera a los otros dos en términos de área total construida, todas sus estructuras son de menor escala que las de los dos últimos.

En términos de complejidad del espacio arquitectónico, las evidencias de superficie nos permiten considerar que dicha complejidad está relacionada con el grado de articulación de unidades de volumen con unidades de área y, en particular, con las plazas hundidas. De acuerdo al Cuadro 1, las estructuras de Cerro Blanco Norte y Cerro Lampay comparten el hecho de articularse a plazas hundidas con tres estructuras de Caballete, dos estructuras de Porvenir y una estructura de Cerro Blanco Centro. Encontramos así que, en términos de compleji- 
dad o elaboración del espacio, las estructuras aisladas guardan más relación con las estructuras de mayor tamaño de los complejos arquitectónicos que con las más pequeñas y sencillas. No existe, por otro lado, dentro de Caballete, Porvenir o Cerro Blanco Centro, algún tipo de estructura que presente niveles de complejidad claramente mayores a las estructuras de Cerro Blanco Norte o Cerro Lampay.

Hay que añadir que al interior de los complejos arquitectónicos de más de una estructura, nos encontramos básicamente con una división binaria, entre montículos piramidales o plataformas con y sin plazas hundidas, pudiendo encontrar así varias estructuras "equivalentes" en términos de complejidad, si bien con diferencias de escala a veces notables.

Esta revisión indica que, para los sitios del Arcaico Tardío en la Zona IV de Fortaleza, las diferencias de escala y complejidad observadas inicialmente, no se correlacionan con las diferencias de escala y complejidad entre las estructuras de dichos sitios. En tal sentido, la aplica- ción de un marco interpretativo basado en la existencia de una estructura jerárquica de centros resulta insuficiente para entender la organización espacial de sitios dentro de la Zona IV. Vale la pena, por lo tanto, considerar otras perspectivas de análisis.

Al observar la distribución de estructuras del Cuadro 3, encontramos una interesante correlación entre las estructuras más grandes y su eventual asociación con plazas hundidas. Nos referimos a las Estructuras 5, 6 y 10 de Caballete, las Estructuras 4 y 7 de Porvenir, la Estructura 1 de Cerro Blanco Centro y las estructuras de Cerro Blanco Norte y Cerro Lampay. Luego, encontramos estructuras sin asociación de plazas hundidas que pueden dividirse en montículos piramidales y plataformas simples.

Tal parece que existe por lo menos una estructura de "primer rango" en cada uno de los sitios. En el caso de Caballete y Porvenir, dentro de las estructuras de primer rango, existe una estructura que destaca por su escala (Estructura 6 de Caballete y Estructura 4 de Porvenir). Si

\section{Cuadro 3}

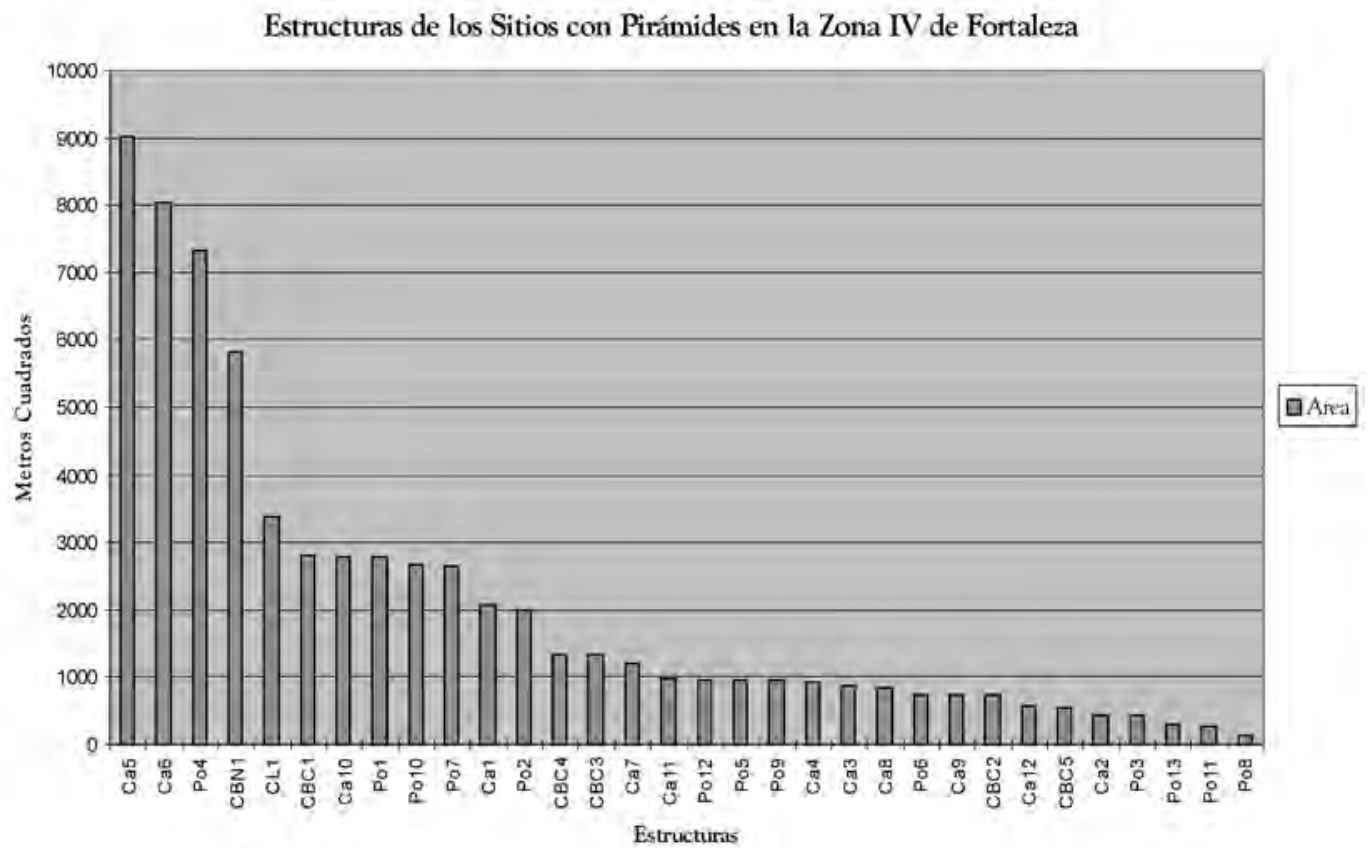


observamos los planos de ambos sitios (Figs. 10 y 13), se trata de estructuras ubicadas en una posición central dentro de ambos complejos. Estas dos líneas de evidencia nos sugieren que puede tratarse de las estructuras "principales" dentro de cada asentamiento.

Un dato adicional a tomar en cuenta es que, por lo menos para cuatro casos, estas "estructuras principales" han sido construidas aprovechando promontorios o elevaciones naturales. Los promontorios han sido aprovechados en Cerro Blanco Norte y Caballete (Estructura 6), mientras que en Cerro Blanco Centro la Estructura 1 se construye sobre la pendiente de un cerro. A esto debemos sumar la ubicación de la estructura de Cerro Lampay, que aprovecha una terraza natural de la quebrada. Por último, la Estructura 4 de Porvenir, un corte de grandes dimensiones realizado en la parte posterior de la estructura, muestra evidencias de roca granítica con fractura laminar, semejante a la que uno puede encontrar en afloramientos rocosos vecinos. En este último caso, debería comprobarse si, efectivamente, se ha aprovechado un montículo natural para el emplazamiento de la estructura.

El hecho de que estas estructuras hayan sido construidas aprovechando elevaciones naturales en el paisaje, constituye un fenómeno singular en términos de "apropiación" del espacio natural por parte de los constructores que merece un estudio particular. Por otro lado, con el objetivo de entender la organización espacial de estos sitios, puede considerarse que, al haber "escogido" emplazamientos de estas características, las estructuras principales parecen corresponder a las construcciones originales o "fundadoras" dentro de cada complejo. Por lo tanto, las siguientes construcciones deben entenderse en función del arreglo o ampliación de un espacio original constituido sólo por las estructuras originales.

Revisando los planos de los sitios, encontramos que en Cerro Lampay (Figura 5) existe un largo muro-plataforma extendido en el eje del muro posterior de la pirámide. En Cerro Blanco
Centro (Figura 6), tenemos un agrupamiento de cuatro estructuras alineadas delante de la estructura principal.

En Porvenir (Figura 10), las estructuras se articulan en dos alineamientos. Uno se encuentra cerca de la Estructura 4 y cuenta con siete estructuras; mientras que el otro, algo más alejado, está orientado en forma paralela al primer alineamiento y cuenta con cinco estructuras. Ambos alineamientos delimitan un área rectangular que, junto con la Estructura 4, otorga al complejo una forma general en "U".

Por su parte, en Caballete (Figura 13), encontramos una estructura al lado derecho de la Estructura 6. Existen otras dos estructuras a lo largo del eje del muro frontal de la Estructura 6. También existen dos conjuntos adicionales de estructuras, cada uno con un volumen central y dos plataformas simples, que están alineados en forma perpendicular a la Estructura 6 . Finalmente, frente a la Estructura 6, encontramos la pequeña Estructura 12. De esta manera, se forma un espacio cuadrangular cerrado entre los diferentes conjuntos de estructuras.

Esta breve descripción muestra que existen algunos patrones comunes -como la construcción de estructuras o componentes asociados, en alineamiento o distribución perpendicular- en relación a las estructuras centrales. Sin embargo, las soluciones finales de organización del espacio son particulares en cada sitio. Por ejemplo, en Cerro Blanco Centro la adición de nuevas estructuras parece "desplazar" a la Estructura 1 o, en todo caso, restringir su acceso. En contraste, en Caballete y Porvenir las estructuras centrales parecen constituirse en los ejes articuladores del espacio arquitectónico en su conjunto.

Podemos inferir entonces que estos sitios experimentaron procesos de crecimiento diferenciados tanto en escala como en el diseño final. De ser así, la explicación de las diferencias en escala y complejidad de estos sitios podría incluir un escenario alternativo al de la red jerárquica: la existencia de diferentes trayectorias, de distinta duración o con distintos fenóme- 
nos sociales y políticos involucrados, dentro del proceso de ocupación y desarrollo socioeconómico de la Zona IV de Fortaleza.

Ese escenario permite considerar que hayan existido diferentes entidades sociales o políticas, representadas en la arquitectura pública existente en estos cinco sitios, con la posibilidad de diferentes grados de interacción entre ellas.

Si este escenario es correcto, es importante indagar acerca de la naturaleza de estas entidades sociales o políticas. Como dijimos antes, cada sitio parece tener una organización espacial particular.

En el caso de Caballete existe una distinción entre pirámides con atrio (Estructuras 1, 5, 6 y 10), tres de ellas asociadas con plazas circulares hundidas. De estas, indicamos que la Estructura 6 se encuentra al centro del complejo y parece ser la primera estructura construida. Por su parte, las Estructuras 1, 5 y 10 presentan plataformas bajas de tamaño variable a sus lados. La articulación de estas dos estructuras varía en cada caso, pero parece ser un patrón consistente de organización en subconjuntos. Esta organización parece ser reproducida a menor escala por la Estructura 12. Por su parte, las Estructuras 7 y 4 aparecen aisladas. Una posible explicación sería que cumplen una función semejante, como estructuras articuladas a la Estructura 6, con la cual parecen estar alineadas. Estas observaciones sugieren que, a nivel general, existe un patrón de articulación de estructuras en subconjuntos marcados por una estructura principal y dos estructuras subordinadas. De ser así, la organización espacial de Caballete se caracterizaría por la coexistencia de cinco subconjuntos relativamente equivalentes en cuanto a complejidad espacial, si bien con diferencias de escala.

En el caso de Porvenir, existen patrones similares. La Estructura 4 es la estructura central, y cuenta con una estructura menor a un costado (Estructura 5). Por su parte, las Estructuras 1, 2 y 7 destacan como estructuras principales, dos de ellas con atrio. Cada una cuenta con estructuras o plataformas asociadas. A diferencia de
Caballete, en este caso, las estructuras asociadas están a un solo lado y unidas arquitectónicamente. Llama la atención, además, la sucesión de estructuras dentro del eje de estos alineamientos. La existencia de la Estructura 5, al costado de la Estructura 4, estaría sugiriendo la adopción de este patrón para la estructura principal.

Tenemos así un patrón de organización de estructuras o de subconjuntos de estructuras con características homólogas y que, por otro lado, pueden variar en escala. Este patrón es significativo ya que las semejanzas formales y estructurales identificadas estarían reflejando el uso de las estructuras para las mismas funciones. Si estos conjuntos o estructuras cumplían funciones similares, su proliferación dentro de un mismo sitio estaría reflejando la concurrencia de distintos grupos o entidades sociales equivalentes que hacían uso de diferentes espacios arquitectónicos autónomos al interior de un espacio común.

Asimismo, las variaciones en escala dentro de las estructuras o conjuntos estarían expresando diferencias en la escala del grupo o entidad social articulada alrededor de dicha estructura. Podrían estar expresando también el mayor o menor número de ampliaciones y remodelaciones de los edificios. De esta forma, la articulación de dichas estructuras dentro de un mismo espacio puede explicarse como la confluencia de entidades sociales equivalentes en un mismo espacio público-ceremonial, en el marco de posibles escenarios de competencia, conflicto y/o negociación, en el cual también existirían entidades o instituciones articuladoras, expresadas en las estructuras principales de cada sitio, cuyo rol y grado de influencia estaría aún por determinarse.

Como corolario, resulta claro que la estructura del montículo-plataforma, con o sin plaza asociada, viene a ser el espacio públicoceremonial representativo de una unidad sociopolítica. Es importante, por lo tanto, tratar de entender la naturaleza de esta unidad espacial, para lo cual se requiere ir más allá del dato de superficie. 


\section{El Arcaico Tardío en la Costa Nor-Central. Revisión y comparaciones}

Los resultados y planteamientos desarrollados hasta el momento merecen ser contrastados con las investigaciones desarrolladas en otras zonas y sitios de la Costa Nor-Central relacionados con el Arcaico Tardío.

Debe notarse que, como en el caso de Fortaleza, la escasez de evidencias de contextos residenciales o funerarios, convenientemente documentadas, ha condicionado un énfasis en el estudio de la arquitectura público-ceremonial como fuente para entender la naturaleza sociopolítica de las sociedades del Arcaico Tardío en la Costa Nor-Central.

Uno de los primeros autores en destacar la relación entre arquitectura y sociedad para esta región es Michael Moseley (1975a), quien al revisar la información del sitio de Áspero, considera que la arquitectura pública allí existente "dramatiza la complejidad social de la vida marítima y refleja sus bases económicas" (Moseley 1975a:117). Robert Feldman desarrolla esta idea adoptando el esquema evolutivo de Elman Service $(1962,1975)$. Feldman plantea que la arquitectura de Áspero refleja la existencia de una "Jefatura" (Feldman 1987:14), idea que va a ser adoptada por otros autores para el conjunto de sociedades del Arcaico Tardío (Haas 1987:32). En contraste, Ruth Shady plantea que para el Arcaico Tardío se estaría desarrollando un "Estado Prístino" en el sitio de Caral, responsable de la integración y unificación política del valle de Supe (Shady 2000:29; Shady et al. 2000:27).

Más allá de las implicancias teóricas de estos planteamientos, es importante indicar que cualquier aproximación a la naturaleza política de estas sociedades requiere definir las características del escenario regional. Con relación a este punto, Shady y sus colegas plantean que, para el valle de Supe, esta dinámica estaría caracterizada por una entidad centralizada alrededor del sitio de Caral, el cual habría adquirido gran prestigio frente a otros sitios y otorgaría unidad política al valle (Shady et al.
2000:26-28). Este planteamiento se basa en un examen de la escala de construcción y diversidad formal de la arquitectura pública identificada en 18 sitios del valle de Supe.

La escala de los sitios de Supe ha sido definida sobre la base de la extensión (en hectáreas) y del volumen total de construcción (definido como "fuerza de trabajo invertida") para cada sitio. A partir de estos cálculos, se establecen seis clases de sitios o "centros urbanos" (Shady et al. 2000:16-20), entre los que destacan los sitios de Caral y Pueblo Nuevo con más del 50\% del total de fuerza de trabajo invertida.

Por su parte, el examen morfológico de la arquitectura de Supe concluye en la definición de 10 tipos (Shady et al. 2000:20-25). De acuerdo con los autores, sitios como Caral o Pueblo Nuevo presentan algunos tipos arquitectónicos exclusivos, como las llamadas "Pirámides Mayores" (Shady et al. 2000:20-21).

La información proporcionada por Shady y sus colegas para el valle de Supe constituye, sin duda, la principal fuente de comparación con relación a los datos de la Zona IV de Fortaleza. Es importante hacer algunas observaciones sobre la información presentada.

La distribución de sitios por "inversión de fuerza de trabajo" para el valle de Supe (Shady et al.2000: Gráfico 2) es comparable con el Cuadro 2 en este trabajo, si bien los parámetros de medición no son los mismos. Por ejemplo, la información de Supe no hace referencia al número de unidades arquitectónicas por sitio. El texto de Shady y sus colegas proporciona planos preliminares de los sitios (Shady et al. 2000:39-48), acompañados de descripciones someras (Shady et al. 2000:34-38) que evidencian la variabilidad en cuanto a número y tamaño de estructuras al interior de estos sitios. Esta variabilidad es ilustrada a través de un cuadro-resumen del tipo de estructuras identificables por cada sitio (Shady et al. 2000: Cuadro 5). Sin embargo, la información acerca de la escala de cada estructura no es presentada de forma desarrollada, sino que es resumida en una 
"suma total" para cada sitio (Shady et al. 2000: Gráfico 2).

Como hemos señalado para el caso de Fortaleza, la presentación sintética del total del área construida por sitio ofrece una visión parcial del proceso de construcción y de inversión de fuerza de trabajo, la cual requiere ser contrastada con una medición de la escala de construcción por cada unidad arquitectónica específica. En ese sentido, la definición de seis "clases" de sitios planteada para el valle de Supe puede ser susceptible de un replanteamiento si es que se incluye un análisis de la "inversión de fuerza de trabajo” por cada unidad arquitectónica. Este tipo de análisis debería estar orientado a responder preguntas como: iestamos realmente ante una división jerárquica con sitios de grandes estructuras vs. sitios con estructuras pequeñas? ¿o puede tratarse de entidades homólogas, con diferentes procesos de desarrollo y/o crecimiento, reflejado en variaciones en el número y tamaño de las estructuras? Dicho de otro modo, ¿estamos ante un escenario semejante al de la Zona IV de Fortaleza o se trata de un escenario con diferencias significativas?

Es importante comentar también el análisis formal de las estructuras en Supe. Shady y sus colegas proponen la existencia de diez tipos arquitectónicos: Pirámide Mayor, Pirámide, Estructura de Plataformas Secuenciales, Estructuras Singulares, Plataforma Cuadrangular con Plaza, Plataforma Cuadrangular, Plataforma Rectangular, Plaza Circular en Serie, Plaza Circular Inscrita y Plaza Circular en Secuencia Vertical. Debe notarse que tanto pirámides como plataformas corresponden básicamente a volúmenes elevados aterrazados, cuya diferencia principal se encuentra en la proporción entre base y altura (Shady et al. 2000:21, 24), salvo el caso del tipo Pirámide Mayor, que incluye la presencia de "alas laterales" (Shady et al. 2000:20). Por otro lado, las llamadas estructuras con plataformas secuenciales presentan como singularidad un énfasis en la diferenciación de espacios por "extensión en plano" antes que por la "elevación de planos", como en el caso de las pirámides o plataformas (Shady et al. 2000:21), algo reproducido en pequeña escala por las estructuras singulares (Shady et al. 2000:22). Por último, se incluyen tres variantes de plazas circulares hundidas, a los que habría de incluir otros mencionados como partes componentes de los tipos anteriores.

Al comparar estos datos con la tipología propuesta para Fortaleza encontramos varias coincidencias. En primer lugar, la existencia de unidades de volumen de tres tipos: Plataformas en Secuencia (lo que en este trabajo se llama Plataforma Aterrazada), Plataformas Simples y Montículos Piramidales. Asimismo, destacan las plazas hundidas como unidades de área articuladas eventualmente con las de volumen.

Shady y sus colegas consideran que la diversidad formal descrita reflejaría diferentes tipos de funciones asociadas con la entidad estatal (Shady et.al. 2000:30). Debe precisarse, sin embargo, que dentro de la variabilidad notada por Shady y sus colegas, tenemos diferencias de tamaño dentro de una misma organización del espacio (por ejemplo, en la relación altura-base para un montículo) y, por otro lado, variantes en la concepción del espacio. Estas últimas corresponden propiamente a una variante formal significativa. En tal sentido, podríamos considerar que la arquitectura de Supe presenta dos variantes principales: la de unidades de volumen elevadas, con o sin asociación de unidades de área, y la de unidades de volumen extendidas en secuencia longitudinal. Shady y sus colegas ilustran que estas variantes parecen tener un patrón de distribución diferenciado al interior de los sitios del valle, y estarían reflejando "dos modelos de centro urbano" (Shady et al. 2000:26, 28).

Por otro lado, la recurrencia de unidades de volumen con formas básicas (pirámides o plataformas), asociadas a unidades de área donde también hay formas características (plazas hundidas), hace que una explicación funcional para la diversidad formal sea problemática. Las carac- 
terísticas formales de las estructuras en cuestión -con espacios abiertos, elevaciones de gran escala o espacios restringidos en la cima- son relacionadas con funciones rituales o ceremoniales. No hay evidencias suficientes para contemplar otro tipo de funciones (administrativas, militares, etc.), características de una entidad estatal.

La variabilidad tipológica de estas estructuras puede ser en parte de origen cronológico, si bien debe comprobarse la anterioridad o posterioridad de algunas formas arquitectónicas en relación a otras dentro de un mismo conjunto. Por otro lado, la coherencia en la organización de los complejos con formas variadas sugiere por lo menos un nivel mínimo de coexistencia de las estructuras a su interior. En ese sentido, debe contemplarse también una explicación corológica, es decir, de la existencia de entidades colectivas con diferentes tradiciones o bagaje tecnológico-cultural, reflejado en diferentes formas de construir espacios arquitectónicos para usos rituales.

Si esta última explicación es correcta, se hace necesario discutir la naturaleza de estas "entidades". En otras palabras, discutir la representatividad social de las unidades arquitectónicas descritas.

Varios investigadores han notado la profusión y diversidad de unidades arquitectónicas que caracterizan a los sitios del Arcaico Tardío en el la Costa Nor-Central. Moseley, por ejemplo, considera que cada edificio estaría identificando la autoridad, prestigio o status de los miembros de la autoridad central (Moseley 1975a:94). Por su parte, Shady y sus colegas contemplan la posibilidad de que las estructuras públicas tengan espacios cerrados exclusivos para las "cabezas de linajes", constituidos como elite gobernante de los centros urbanos (Shady et al. 2000:27). Establecer una relación de identidad entre un edificio público y una persona requiere de indicadores arqueológicos claros, tales como la articulación de tumbas o residencias de élite con los edificios públicos en cues- tión. Hasta el momento, no se han hallado este tipo de indicadores en ninguna estructura del Arcaico Tardío en la Costa Nor-Central. En efecto, la ausencia de estos indicadores lleva a Feldman a considerar que la dinámica de poder en un sitio como Áspero "prioriza labores corporativas o comunales sobre el bienestar individual de las élites" (Feldman 1985:84-85; ver también Feinman 2000:215). Desde otro punto de vista, Richard Burger plantea que los edificios públicos del Arcaico Tardío deben ser considerados como expresiones físicas y metafóricas de la unidad e identidad comunal (Burger 1992:38).

Estas consideraciones coinciden con lo planteado para los sitios de la Zona IV de Fortaleza. Más allá de la denominación que se use para identificar a los grupos o entidades sociales, es sugerente considerar a las unidades arquitectónicas en cuestión como referentes de la totalidad de dichas entidades antes que referentes de individuos o sub-grupos (v.g., elites). En tal sentido, las investigaciones y las discusiones futuras deberán incluir una búsqueda por definir la escala y naturaleza socio-política de los grupos o entidades colectivas responsables de la construcción de cada una de las estructuras en cuestión.

Respecto a este último punto, es importante recordar la usual relación que se establece entre actividad constructiva y centralización (Feldman 1985:82; Haas 1987:32; Moseley 1975a:79-80; Shady et.al. 2001:726), como argumento recurrente para asociar arquitectura pública con complejidad social. Esta relación, sin embargo, no es mecánica ni simple, y requiere del análisis de varios aspectos que, generalmente, no son posibles de abordar con datos superficiales. En efecto, el grado de centralización de una actividad está relacionado con la coordinación y/o articulación de diferentes actividades o tareas. Esta coordinación se refleja en la variabilidad de los materiales constructivos utilizados, así como su disposición y/o distribución dentro de la construcción. Ambos tipos de datos nos deben informar sobre el número y diversidad de participantes en la cons- 
trucción, así como la naturaleza de su participación. Existen varios estudios de este tipo para el caso andino (Cavallaro y Shimada 1988; Moseley 1975b; Shimada 1994) que reflejan cómo unidades arquitectónicas de escalas similares pueden ser producto de diferentes procesos constructivos que corresponden a diferentes entidades sociales y políticas.

Por otro lado, recientes contribuciones cuestionan la validez universal del principio que asume la centralización como el sistema más óptimo para la construcción de obras públicas, anotando su reducida flexibilidad y falta de respuesta a situaciones cambiantes. En contraste, se han evaluado las ventajas de sistemas que impliquen la división de toma de decisiones en unidades de trabajo no superpuestas, con autonomía para optimizar sus propias estrategias y con niveles mínimos de coordinación entre ellas. Hay que recalcar que este tipo de sistemas organizativos están frecuentemente ligados a actividades constructivas enmarcadas o concebidas como actividades rituales (Wills 2000:36-37).

\section{A manera de síntesis}

Luego de esta revisión, podemos plantear algunas ideas sobre el estado de la cuestión arqueológica con relación a las sociedades tempranas de la Costa Nor-Central.

En primer lugar, puede afirmarse la existencia de una tradición arquitectónica consolidada en esta región, con algunos complejos de más de 10 estructuras públicas. Estos complejos varían en su extensión, escala constructiva, distribución y organización espacial de estructuras. Tienen en común, por otro lado, una tendencia al alineamiento de estructuras, hecho que sugiere un importante grado de articulación o, inclusive, planificación del conjunto. Al interior de estos complejos destaca como unidad básica la estructura compuesta por un montículo-plataforma y una plaza, frecuentemente hundida. La significativa variabilidad formal en este tipo de estructura compuesta es quizás uno de los temas centrales de investigación para el futuro.
La existencia de entidades centralizadas, con el control de valles o regiones enteras, resulta discutible por la falta de definición clara de las funciones o roles de una entidad central, así como de correlatos materiales. En contraste, una integración cultural, e incluso ideológica, de los sitios coexistentes puede explicarse por el grado y dinámica de la interacción inter e intra valles, antes que por un proceso de expansión o difusión. En un contexto de estas características, la variedad en tamaño, número y formas de estructuras en los sitios registrados, puede estar indicando diferentes derroteros o trayectorias dentro del escenario de interacción sugerido.

Otro aspecto importante para entender a las sociedades que construyeron estas estructuras es el proceso de crecimiento y organización interna de los complejos arquitectónicos. En el caso de la Zona IV de Fortaleza, se ha propuesto, de manera tentativa, algunas posibilidades para entender la secuencia de construcción de los edificios. Sobre la base de esta propuesta, planteamos que estos complejos son el resultado de la congregación o convergencia de entidades socio-políticas diferenciadas, que coinciden en el uso de un espacio común para la construcción de sus propios espacios rituales. El carácter tentativo de esta propuesta sólo puede ser resuelto con datos de excavación que permitan una correlación cronológica más precisa de los eventos constructivos llevados a cabo, así como un registro más detallado de las semejanzas y diferencias de los espacios construidos.

En una escala más específica, la estructura constituida por montículo y plaza adquiere una relevancia particular en estos complejos al representar, posiblemente, las entidades sociopolíticas básicas del entramado social de esta región para el Arcaico Tardío.

Se hace pues necesario estudiar la naturaleza del proceso de construcción y la organización espacial de estas estructuras, con el fin de identificar el tipo de actividades llevadas a cabo, así como el grado y tipo de participación de los grupos humanos involucrados en dichas activi- 
dades. Sólo después de la respuesta a estos interrogantes, estaremos en posibilidad de entender la naturaleza social y/o política del tipo de entidades colectivas que estuvo detrás de estos proyectos constructivos.

\section{El surgimiento de sociedades complejas. Nuevas perspectivas teóricas}

La preocupación por entender a las sociedades del Arcaico Tardío se explica, en gran medida, por su relevancia actual dentro del debate sobre el origen y surgimiento de sociedades complejas en los Andes Centrales y, en particular, sobre el surgimiento del Estado. Es significativo que este debate haya sido planteado en términos de la disyuntiva jefaturas vs. estados prístinos.

Una discusión en estos términos parece recoger la influyente propuesta de Elman R. Service $(1962,1975)$, que clasifica a las sociedades en cuatro estadios evolutivos: Banda, Tribu, Jefatura y Estado. La propuesta de Service supone que el fenómeno clave en el proceso de evolución es la institucionalización del liderazgo centralizado, en el medio de relaciones jerárquicas (Service 1975:8-11) y actividades redistributivas (Service 1975:75). Esta propuesta fue acogida en la arqueología y desarrollada dentro de la teoría de sistemas (v.g., Flannery 1972; Johnson, 1982; Wright 1978, 1984), asumiéndose que el surgimiento de sociedades complejas implica el incremento de la segregación y la centralización al interior de una sociedad (Flannery 1972:409).

La propuesta original de Service fue cuestionada por su lógica funcional (Carneiro 1970, 1981; Earle 1977, 1978; Yoffee 1979), por su naturaleza tipológica (McGuire 1983), y por la dificultad de incluir en su esquema a toda sociedad existente (Feinman y Neitzel 1984). Estas críticas abrieron campo a nuevas reflexiones.

En primer lugar, si el surgimiento de la complejidad social tiene que ver con el surgimiento de la desigualdad y las relaciones jerárquicas iéstas aparecen con las llamadas jefaturas o pueden ser observadas en estadios anteriores? Esto lleva a revisar el concepto de "sociedad igualitaria" (Flanagan 1989), anotando que las diferencias sociales o las relaciones jerárquicas frecuentemente preceden a la institucionalización de la desigualdad, pudiendo existir dentro de contextos comúnmente definidos como igualitarios (Paynter 1989:367). Por su parte, la complejidad se define principalmente por el grado de diferenciación interna de un sistema y lo intricado de las relaciones entre sus elementos componentes (Paynter 1989:369). Desde esta perspectiva, la jefatura ya no puede ser vista como el estadio complejo inicial, sino como el final de un proceso de surgimiento de la complejidad (Hayden 1995).

Una segunda reflexión tiene que ver con los factores de surgimiento y desarrollo de la complejidad social. El cuestionamiento de las explicaciones funcionales o estructurales está relacionado con un interés por entender la generación de relaciones de poder como factor de desarrollo de sociedades complejas (Earle 1991:14). Este énfasis en el estudio de las estrategias de poder implica, a su vez, asumir la posible existencia de diferentes trayectorias en el surgimiento y control del poder social, con la consecuente existencia de desarrollos socio-políticos complejos alternativos (Blanton 1998; Blanton et al. 1996; Feinman 1995; Gilman 1991; Yoffee 1993). Una implicancia inmediata de esta posibilidad es la superación de esquemas tipológicos evolutivos de validez universal.

Una tercera reflexión tiene que ver con el rol de la centralización del poder y su supuesto valor universal en el desarrollo de sociedades complejas. Recientes investigaciones han notado la dificultad de aplicar este supuesto para entender realidades complejas en lugares como el África Subsahariana o el Sureste Asiático (McIntosh 1999; White 1995). Como resultado, se han planteado nuevos marcos teóricos para entender la diversidad de trayectorias hacia la complejidad.

Dos de los principales marcos teóricos desarrollados son la Teoría Procesal Dual y la Heterarquía. 
La Teoría Procesual Dual (Blanton 1998; Blanton et al. 1996; Feinman 1995, 2000) recoge la preocupación por entender la relación dinámica entre acción humana y estructura social (Bourdieu 1977; Giddens 1984). La propuesta parte de reconocer que las sociedades "igualitarias" se caracterizan básicamente por la existencia de mecanismos niveladores que impiden la institucionalización de situaciones internas de desigualdad. De igual forma, dentro de estas sociedades existen condiciones internas y externas que cuestionan permanentemente estos mecanismos y propugnan la institucionalización de desigualdades (Feinman 1995:262). En este contexto, la acción política se desarrolla sobre la base de un bagaje cultural adquirido por socialización y, a su vez, actúa sobre él, propiciando su mantenimiento y reproducción o, por el contrario, su transformación (Blanton et al. 1996:2).

De acuerdo con estos principios, las estrategias de poder tienen una naturaleza dual que genera caminos alternativos hacia la complejidad. Estos caminos se marcan por formas de ejercicio del poder excluyentes y corporativas. La estrategia excluyente se caracteriza por el monopolio de fuentes de poder y la correspondiente centralización. Los autores llaman la atención sobre una estrategia alternativa, de tipo corporativo, donde el poder es compartido a través de diferentes grupos y sectores de una sociedad.

Esta estrategia de tipo corporativo se explica por la pervivencia de comportamientos igualitarios en sociedades complejas. Por comportamiento igualitario se entiende una serie de medidas que limitan el poder integral y restringen el ejercicio de poder excluyente (Blanton 1998:147-148, 151-152), el cual se da dentro del marco de una estructura de autoridad construida sobre líneas corporativas basadas en un código cognitivo que limita el control del poder (Blanton 1998:152). Así, las estrategias corporativas ofrecen un reducido potencial para monopolizar poder. Ofrecen también un alto grado de apertu- ra a posiciones de liderazgo y una relativa autonomía de los subsistemas dentro de una estructura de control político (Blanton 1998:147).

El concepto de Heterarquía se desarrolla en el marco del paradigma sistémico, como alternativa a la noción de jerarquía como principio organizador universal. Heterarquía alude a la relación entre dos o más elementos nojerarquizados que, sin embargo, tienen el potencial para ser jerarquizados en diferentes maneras (Crumley 1979:144, 1995:3). En otras palabras, se trata de una relación entre componentes diferenciados que no conlleva, necesariamente, a un ordenamiento vertical. En caso de existir, las relaciones jerárquicas pueden variar de acuerdo a requerimientos del sistema (v.g., su contexto de aparición o su función) y pueden estar articuladas dentro de un universo mayor no-jerarquizado.

Contemplar escenarios heterárquicos dentro de una sociedad compleja implica reconocer que las formas de orden y poder no tienen que ser necesariamente verticales y que los grupos sociales o políticos diferenciados no tienen que estar permanentemente jerarquizados entre ellos. En tal sentido, el principio de heterarquía permite identificar fenómenos tales como la "diferenciación lateral u horizontal" dentro de un grupo heterogéneo o la formación de "jerarquías flexibles" dentro de una estructura de poder (White 1995:104). Asimismo, los mecanismos de control y poder en una sociedad compleja pueden ser tanto centralizados como dispersos (White 1995:117). Por otro lado, estos mismos mecanismos pueden no ser de naturaleza estructural y adquirir una dimensión contextual. Esto significa que las relaciones de poder dentro de una sociedad se encuentran permanentemente interpeladas y son susceptibles de replanteamiento (Crumley 1995:3).

En términos concretos, el concepto de heterarquía permite explicar fenómenos como la existencia de poderes contrapuestos (v.g., Líderes espirituales vs. grupos de poder comercial) (Crumley 1995:3), la formación de grupos 
de poder competitivos como sociedades secretas o parcialidades (McIntosh 1999:11), o la dispersión de mecanismos de control dentro de sociedades complejas (White 1995:117).

Es importante notar que cuando se habla de heterarquía no se habla de un nuevo tipo o modelo de estructura social. Se trata más bien de un principio organizativo (Brumfiel 1995:128) o un concepto analítico que expande nuestra comprensión de las dinámicas sociopolíticas (Small 1995:71). No existe, por lo tanto, un tipo de sociedad heterárquica, sino la manifestación, en distintas sociedades, de distintas formas de organización heterárquica.

\section{Balance y perspectivas}

Las reflexiones reseñadas implican reformular nuestras interrogantes acerca del surgimiento de sociedades complejas. La pregunta acerca de "cuán compleja era la sociedad X" pierde relevancia ante la duda de "cómo es que la sociedad X era compleja” (Rautman 1998:326). En otras palabras, incide en una definición mucho más precisa de las características sociales y políticas de la sociedad en estudio para poder aproximarse a explicaciones causales de su formación. Estas inquietudes han sido planteadas por varios investigadores para el área andina (Bawden 1994; Dillehay 2001; Silverman 1993). Sería conveniente que este tipo de inquietudes sean introducidas en el debate sobre el Arcaico Tardío en la Costa Nor-Central.

El estado actual de las evidencias para este período y región, dominado por datos de superficie, no permite desarrollar propuestas teóricas muy elaboradas. Sin embargo, plantear el debate en términos de la identificación de jefaturas o estados, limita las posibilidades de entendimiento. Por el contrario, a partir de las reflexiones expuestas se pueden abrir nuevas perspectivas de investigación para entender las características específicas del desarrollo socio-político de la Costa Nor-Central para el Arcaico Tardío.

En primer lugar, al asumir que las estructuras de poder no son inmutables u homeostáticas, sino que son dinámicas y susceptibles de constante cambio, se hace indispensable obtener un registro cronológico detallado y fino de la construcción y funcionamiento de las estructuras arquitectónicas descritas, así como de sus cambios y continuidades. Las evidencias de superficie o enfoques puramente sincrónicos son, en esta perspectiva, insuficientes.

En segundo lugar, debido al cuestionamiento del valor universal de los modelos tipológicos y asumiendo cómo las estructuras sociopolíticas pueden variar de acuerdo a cada contexto, se hace necesario especificar la escala del análisis utilizada. En el caso de los sitios de la Costa NorCentral, debe especificarse cuando se está analizando la organización socio-política alrededor de una estructura, alrededor de un complejo o alrededor de una región. No es conveniente extrapolar resultados de un nivel de análisis a otros.

Por la misma razón, se hace necesario especificar el contexto y las funciones de las relaciones de poder estudiadas. Para el caso analizado, se asume que las estructuras son de carácter ceremonial. Es decir, se trataría de espacios construidos para la conducción de rituales. Esto implica entender el ritual como actividad humana, sus connotaciones sociales, políticas y sus patrones. También implica entender su articulación y organización en el espacio, y las implicancias políticas que esto trae. Por último, implica evaluar la representatividad de las relaciones de poder manifestadas en actividades rituales dentro de una estructura de poder.

Como puede observarse, los nuevos requerimientos teóricos y metodológicos revisados implican un camino más largo para entender la complejidad emergente. Abren más preguntas que las respuestas que generan. Sin embargo, nos ayudan a mirar críticamente supuestos y generalizaciones anteriormente asumidas y, de esta manera, enriquecen mucho más el marco conceptual y analítico para entender los orígenes de nuestras formas complejas de organización social y política. 


\section{Agradecimientos}

Los trabajos de prospección y mapeo en el valle de Fortaleza fueron patrocinados y financiados por la Dirección Académica de Investigación de la Pontificia Universidad Católica del Perú, a cargo de la Doctora Margarita Suárez. Los equipos de topografía fueron prestados por el Gabinete de Topografía de la misma universidad, a cargo del Ingeniero Juan Carlos Dextre. En el valle de Fortaleza contamos con el apoyo y facilidades de la Empresa Agroindustrial Paramonga, en particular de la señora Hasel Rosas y del ingeniero Julián Horna. Los trabajos de campo contaron con la asistencia profesional de la arqueóloga Cristina Rospigliosi y la participación de Marilyn Herrera y Claudia Pereyra, estudiantes del Programa de Arqueología de la Pontificia Universidad Católica del Perú. A todas las personas nombradas, mi más sincero agradecimiento.

\section{Bibliografía}

Álvarez Vera, Alcídez y Juan E. Espinoza

1997 Mandinga: Un Asentamiento Tipo Aldas en el valle de Huarmey. Mauq'a Llaqta 1:27-49.

Bawden, Garth

1994 La Paradoja Estructural: La Cultura Moche como Ideología Política. En Moche: Propuestas y Perspectivas, Uceda, Santiago y E. Mujica (eds.), pp. 389-412. Travaux de l'Institut d'Etudes Andines 79, Lima.

Blanton, Richard E.

1998 Beyond Centralization. Steps toward a Theory of Egalitarian Behavior in Archaic States. En Archaic States, G. M. Feinman y J. Marcus (eds.), pp. 135-172. School for American Research, Santa Fe.

Blanton, Richard E., Gary M. Feinman, Stephen A. Kowalewski y Peter N. Peregrine

1996 A Dual-Processual Theory for the Evolution of Mesoamerican Civilization. Current Anthropology $37: 1-14$.
Bourdieu, Pierre

1977 Outline of a Theory of Practice. Reimpreso. Cambridge University Press. Publicado originalmente en francés como Esquisse d'une Théorie de la Pratique, Précédé de Trois Etudes d'ethnologie Kabyle, 1972, Librairie Droz, Switzerland.

Brumfiel, Elizabeth M.

1995 Heterarchy and the Analysis of Complex Societies: Comments. En Heterarchy and the analysis of Complex Societies, R. M. Ehrenreich, C. L. Crumley y J. E. Levy (eds.), pp. 125-131. Archaeological Papers of the American Anthropological Association 6, Arlington.

Burger, Richard L.

1992 Chavin and the Origins of Andean Civilization. Thames and Hudson, Londres.

Carneiro, Robert L.

1970 A Theory of the Origin of the State. Science 169: 733-738.

Carneiro, Robert L.

1981 The Chiefdom: Precursor of the State. En The Transition to Statehood in the New World, G. D. Jones y R. R. Kautz (eds.), pp. 37-79. Cambridge University Press, Cambridge.

Cavallaro, Raffael e Izumi Shimada

1988 Some Thoughts on Sican Marked Adobes and Labor Organization. American Antiquity 53 (1):75-101.

Crumley, Carole L.

1979 Three Locational Models: An Epistemological Assessment for Anthropology and Archaeology. En Advances in Archaeological Method and Theory, M. B. Schiffer (ed.), pp. 141-173, vol. 3. Academic Press, New York.

Crumley, Carole L.

1995 Heterarchy and the Analysis of Complex Societies. En Heterarchy and the Analysis of Complex Societies, R. M. Ehrenreich, C. L. Crumley y J. E. Levy (eds.), pp. 1-5. Archeological Papers of the American Anthropological Association 6, Arlington. 
Dillehay, Tom

2001 Town and Country in Late Moche Times: A View from Two Northern Valleys. En Moche Art and Archaeology, J. Pillsbury (ed.), pp. 259-283. National Gallery of Art, Washington D. C.

Earle, Timothy K.

1977 A Reappraisal of Redistribution: Complex Hawaiian Chiefdoms. En Exchange Systems in Prehistory, T. K. Earle y J. E. Ericcson(eds.), pp. 213-232. Academic Press, New York.

Earle, Timothy K.

1978 Economic and Social Organization of a Complex Chiefdom: The Halelea District, Kana'i, Hawaii. Anthropological Papers, 63. Museum of Anthropology. University of Michigan. Ann Arbor.

Earle, Timothy K.

1987 Chiefdoms in Archaeological and Ethnological Perspective. Annual Reviews of Anthropology 16:279-308.

Earle, Timothy K.

1991 The Evolution of Chiefdoms. En Chiefdoms: Power, Economy and Ideology, T. K. Earle (ed.), pp. 1-15. Cambridge University Press, Cambridge.

Feinman, Gary M.

1995 The Emergence of Inequality : A Focus on Strategies and Processes. En Foundations of Social Inequality, T. D. Price y G. M. Feinman (eds.), pp. 255 279. Plenum Press, New York.

Feinman, Gary M.

2000 Dual-Processual Theory and Social Formations in the Southwest. En Alternative Leadership Strategies in the Prehispanic Southwest, B. J. Mills (ed.), pp. 207-224. The University of Arizona Press, Tucson.

Feinman, Gary M. y Jill Neitzel

1984 Too Many Types : An Overview of Sedentary Prestate Societies in the Americas. En Advances in Archaeological Method and Theory, M. B. Schiffer (ed.), pp. 39-102, vol. 7. Academic Press, Nueva York.
Feldman, Robert

1980 Aspero, Peru: Architecture, Subsistence Economy and Other Artifacts. Tesis Doctoral Inédita, Harvard University, Cambridge.

Feldman, Robert

1985 Preceramic Corporate Architecture: Evidence for the Development of Nonegalitarian Social Systems in Peru. En Early Ceremonial Architecture in the Andes, C. Donnan (ed.), pp. 71-92. Dumbarton Oaks, Washington D. C.

Feldman, Robert

1987 Architectural Evidence for the Development of Non-egalitarian Social Systems in Coastal Peru. En The Origins and Development of the Andean State, J. Haas, S. Pozorski y T. Pozorski (eds.), pp. 9-14. Cambridge University Press, Cambridge.

Flanagan, James G.

1989 Hierarchy in Simple "Egalitarian" Societies. Annual Review of Anthropology 18:245266.

Flannery, Kent V.

1972 The Cultural Evolution of Civilizations. Annual Review of Ecology and Systematics 3:399-426.

Giddens, Anthony

1984 The Constitution of Society. Cambridge University Press, Cambridge.

Gilman, Antonio

1991 Trajectories towards Social Complexity in the Later Prehistory of the Mediterranean. En Chiefdoms: Power, Economy and Ideology, T. K. Earle (ed.), pp. 146-168. Cambridge University Press, Cambridge.

Haas, Jonathan

1987 The Exercise of Power in Early Andean State Development. En The Origins and Development of the Andean State, J. Haas, S. Pozorski y T. Pozorski (eds.), pp. 31-35. Cambridge University Press, Nueva York.

Hayden, Brian

1995 Pathways to Power : Principles for 
Creating Socioeconomic Inequalities. En Foundations of Social Inequality, T. D. Price y G. M. Feinman (eds.), pp. 15-86. Plenum Press, New York.

Johnson, Gregory A.

1982 Organizational Structure and Scalar Stress. En Theory and Explanation in Archaeology, C. Refrew, M J. Rowlands and B. J. Seagraves (eds.), pp. 389-421. Academic Press, New York.

Kaulicke, Peter

1994 Los Orígenes de la Civilización Andina. Arqueología del Perú. Tomo 1 de Historia General del Perú, José Antonio del Busto (editor general). Brasa, Lima.

Kosok, Paul

1965 Life, Land and Water in Ancient Peru. Long Island University Press, New York.

Lumbreras, Luis Guillermo

1989 Chavín de Huántar en el Nacimiento de la Civilización Andina. Instituto Andino de Estudios Arqueológicos, Lima.

McGuire, Randall H.

1983 Breaking Down Cultural Complexity : Inequality and Heterogeneity. En Advances in Archaeological Method and Theory, M. B. Schiffer (ed.), pp. 91-142, vol. 6. Academic Press, Nueva York.

McIntosh, Susan K.

1999 Pathways to Complexity : An African Perspective. En Beyond Chiefdoms. Pathways to Complexity in Africa, S. K. McIntosh, (ed.) pp. 1-23. Cambridge University Press, Carmbridge.

Moseley, Michael E.

1975a The Maritime Foundations of Andean Civilization. Cummings, Menlo Park.

Moseley, MichaelE.

1975b Prehistoric Principles of Labor Organization in the Moche Valley, Peru. American Antiquity 40 (2):191-196.

Moseley, Michael E. y Gordon R. Willey

1973 Aspero, Peru: A Reexamination of the Site and its Implications. American Antiquity 38 (4): 452-568.

Paynter, Robert

1989 The Archaeology of Equality and Inequality. Annual Reviews of Anthropology 18: 369-399.
Pozorski, Shelia y Thomas Pozorski

1987 Early Settlement and Subsistence in the Casma Valley, Peru. Iowa Press, Iowa City.

Rautman, Alison E.

1998 Hierarchy and Heterarchy in the American Southwest: A Comment on McGuire and Saitta. American Antiquity 63:325-333.

Service, Elman R.

1962 Primitive Social Organization : An Evolutionary Perspective. Random House, Nueva York.

Service, Elman R.

1975 Origins of the State and Civilization: The Process of Cultural Evolution. Norton, Nueva York.

Shady, Ruth

2000 Sustento Socioeconómico del Estado Prístino de Supe-Perú. Las Evidencias de Caral-Supe. Arqueología y Sociedad 13:49-66.

Shady, Ruth y Carlos Leyva (editores)

2003 La Ciudad Sagrada de Caral-Supe. Los Orígenes de la Civilización Andina y la Formación del Estado Prístino en el Antiguo Perú. INC-Proyecto Especial Arqueológico Caral-Supe, Lima.

Shady, Ruth, Camilo Dolorier, Fanny Montesinos y Lyda Casas S.

2000 Los Orígenes de la Civilización en el Perú. El Area Norcentral y el Valle de Supe durante el Arcaico Tardío. Arqueología y Sociedad 13:13-48.

Shady, Ruth, Jonathan Haas y Winifried Creamer

2001 Dating Caral, a Preceramic Site in the Supe Valley on the Central Coast of Peru. Science 292: 723-726.

Shimada, Izumi

1994 Pampa Grande and the Mochica Culture. University of Texas Press, Austin.

Silverman, Helaine

1993 Patrones de Asentamiento en el Valle de Ingenio, cuenca del Río Grande de Nazca: Una Propuesta Preliminar. Gaceta Arqueológica Andina 23:103-124.

Small, David B.

1995 Heterarchical Paths to Evolution : The Role of External Economies. En 
Heterarchy and the Analysis of Complex Societies, R. M. Ehrenreich, C. L. Crumley y J. E. Levy (eds.), pp : 71-85. Archaeological Papers of the American Anthropological Association 6, Arlington.

Vega-Centeno, Rafael

1995 Arquitectura Monumental y Arte Figurativo del Formativo Temprano en la Costa Nor-Central del Perú. Una Aproximación a la Definición de Unidades Cronológicas. Tesis de Licenciatura Inédita, Pontificia Universidad Católica del Perú.

Vega-Centeno, Rafael

1999 Punkurí en el Contexto del Formativo Temprano de la Costa Nor-Central del Perú. Gaceta Arqueológica Andina 25:521.

Vega-Centeno, Rafael, Luis Felipe Villacorta, Luis Cáceres, Giancarlo Marcone

1998 Arquitectura Monumental Temprana en el Valle Medio de Fortaleza. Boletín de Arqueología PUCP 2:219-238.

White, Joyce C.

1995 Incorporating Heterarchy into Theory on Socio-Political Developmment : The Case from Southeast Asia. En Heterarchy and the Analysis of Complex Societies, R. M. Ehrenreich, C. L. Crumley y J. E. Levy, (eds.) pp: 101-123. Archaeological Papers of the American Anthropological Association 6, Arlington.

Willey, Gordon R. Y John M. Corbett

1954 Early Ancon and Supe Culture. Columbia University Press, New York.

Williams, Carlos

1972 La Difusión de los Pozos Ceremoniales en la Costa Peruana. Apuntes Arqueológicos 2:1-9.

Williams, Carlos

1980 Arquitectura y Urbanismo en el Antiguo Perú. En Historia del Perú, Tomo 8:369. 585. Editorial Juán Mejía Baca, Barcelona.

Williams, Carlos

1985 A Scheme for the Early Monumental Architecture of the Central Coast of Peru. En Early Ceremonial Architecture in the Andes, C. Donnan (ed.), pp. 227-240.

Dumbarton Oaks, Washington D. C.

Williams, Carlos

1988 Inicios de la Tradición Arquitectónica Andina. En Arquitectura y Arqueología. Pasado y Futuro de la Construcción en el Perú, V. Rangel (ed.), pp. 27-34. Universidad de Chiclayo, Chiclayo.

Williams, Carlos y Manuel Merino

1979 Inventario, Catastro y Delimitación del Patrimonio Arqueológico del Valle de Supe. Manuscrito Inédito. Instituto Nacional de Cultura, Lima.

Wills, W. H.

2000 Political Leadership and the Construction of Chacoan Great Houses, AD. 1020-1140. En Alternative Leadership Strategies in the Prehispanic Southwest, editado por B. Mills, pp. 19. 44. University of Arizona Press, Tucson.

Wright, Henry T.

1978 Toward an Explanation of the Origin of the State. En Origins of the State: The Anthropology of Political Evolution, R. Cohen y E. R. Service (eds.), pp. 49-68. Institute for the Study of Human Issues, Philadelphia.

Wright, Henry T.

1984 Prestate Political Formations. En On the Evolution of Complex Societies: Essays in Honor of Harry Hoijer 1982, T. K. Earle (ed.), pp. 41-77. Undena, Malibu.

Yoffee, Norman

1979 The Decline and Rise of Mesopotamian Civilization: An Ethnoarchaeological Perspective on the Evolution of Social Complexity. American Antiquity 44 : 5 35.

Yoffee, Norman

1993 Too Many Chiefs? (or Safe Texts for the '90s). En Archaeological Theory: Who Sets the Agenda?, N. Yoffee y A. Sherratt (eds.), pp. 60-78. Cambridge University Press, Cambridge. 